\title{
Nanostructured Functional Materials for Advanced Three-Dimensional (3D) Solar Cells
}

\author{
Jared Jaksik $^{1}$, H. Justin Moore ${ }^{1}$, Tarek Trad ${ }^{1}$, Okenwa I. Okoli ${ }^{2}$, M. Jasim Uddin ${ }^{1 *}$ \\ ${ }^{1}$ Department of Chemistry, University of Texas Rio Grande Valley, Edinburg, TX 78539, United \\ States \\ ${ }^{2}$ Department of Industrial and Manufacturing Engineering, FAMU-FSU College of Engineering, \\ Florida State University, Tallahassee, FL 32310, United States
}

*Corresponding author: jasim.uddin@utrgv.edu, Phone: 956-882-7772 Fax: 956-882-6692

\begin{abstract}
:
Advancements in dye-sensitized solar cell (DSSC) technology are occurring at an everincreasing rate, as the development of novel carbon-based materials, the increasing research into new 3D surface morphologies and cell design, and the focus on the development of new sensitizers and electrolytes have allowed many new possibilities for DSSCs. Solar cells that are three-dimensionally structured offer significant advantages over traditional crystalline / semicrystalline panels in that they can convert incident photons that strike them at large incident angles, can be flexible / used in applications which require non-rigid materials, and can be substantially cheaper to produce than traditional panels, especially with the replacement of more expensive, traditional electrode materials by carbon materials in the working / counter electrode. The use of carefully selected and engineered sensitizers like quantum dots with these threedimensionally structured solar cells have seen them achieve ever-increasing power conversion efficiencies, and it's likely that they will soon rival traditional crystalline / semi-crystalline panels for both mass power generation and use in more niche applications such as flexible photovoltaic textile fibers. This review covers DSSCs constructed with several different materials, and the advantages and disadvantages of a variety of cell designs.
\end{abstract}

\section{Keywords:}

Power wire, 3D solar cells, CNT based PV cells, wearable solar cells, green energy 


\section{Table of Contents:}

1. Introduction

2. DSSC Background

2.1 Electrodes

2.2 Electrolytes

2.3 Sensitizers

3. Advanced Materials for DSSC's

3.1 Carbon Materials

3.2 Inorganic Materials

3.3 Polymer Based DSSC's

3.4 Fiber Based DSSC's

3.5 Glass Based DSSC'S

4. CNT-Based 3-D Solid State Solar Cells

5. Conclusion

6. References

\section{Introduction}

The world's need for energy is ever increasing, and currently about $80 \%$ of this need is met through the use of fossil fuels [1,2]. Coal, in particular, accounts for the majority of electricity production, and holds a $42 \%$ margin over all other energy sources used to generate electricity, which is unlikely to change in the immediate future. In order to prepare for the eventual exhaustion of non-renewable fossil fuels, scientific research has increasingly shifted towards inexhaustible / renewable sources. In addition, renewable sources such as hydroelectric, geothermal, wind, and solar power are "green" in the sense that they don't release greenhouse gases and don't contribute to global warming, unlike fossil fuels. These renewable sources continue to be developed and show great promise for future large-scale electricity production [3]. With ever growing demand for renewable and clean energy, it is inevitable that scientific progress will make these sources viable for energy production. From the previously listed clean, renewable energy sources, solar has seen the most consumer availability and widespread utilization [4]; one could attribute this to solar energy being available everywhere unlike wind, 
geothermal, and hydroelectric which require specific environmental characteristics to be feasible. The production of inexhaustible clean solar energy using advanced photovoltaics and concentrated solar power generating systems will make solar production cheaper and more widespread in the coming years. Although only $1 \%$ of energy production was reported to be solar-derived in 2013, solar power is projected to become the largest source of energy by the year 2050, with solar photovoltaics and concentrated solar power generation contributing $16 \%$ and $11 \%$ respectively to global energy production $[5,6]$. Because of the growing importance of solar energy, the development of new solar technologies (particularly those not based on traditional solid crystalline / semi-crystalline flat substrates) is proceeding rapidly, with several important breakthroughs in recent years.

\section{Solar Energy Conversion \& DSSC Background}

Solar energy depends on the conversion of photons into direct current electrical energy via the photovoltaic (PV) effect. This conversion can be accomplished through various means; the most efficient and widely used method employs crystalline / polycrystalline solar panels, which can achieve a solar-to-electrical energy conversion efficiency of up to 25\% [7]. Crystalline and polycrystalline solar panels currently make up $90 \%$ of commercial solar power production; however, the materials, manufacturing, and installation costs are too high for the average consumer [8]. Alternatives to traditional crystalline / polycrystalline solar cells include semiconductor quantum dots [9], organic semiconductors (with efficiencies of up to 10.7\%) [10,11], and dye sensitized solar cells which achieve moderate conversion efficiency at decreased environmental impact and production cost [12]. Additionally, several technologies are able to achieve a similar conversion efficiency even when the incident angle of the light striking them is large.

In the late 1960's it was discovered that illuminated organic dyes will produce electric current at the interface with an oxide electrode. This led to the construction of electrochemical cells known as dye sensitized solar cells (DSSCs) [13]. Over time DSSCs have gained considerable interest (Figure 1) because they are more cost effective than traditional crystalline / polycrystalline panels, and have power conversion efficiencies (PCEs) of up to 13\% [14]. 


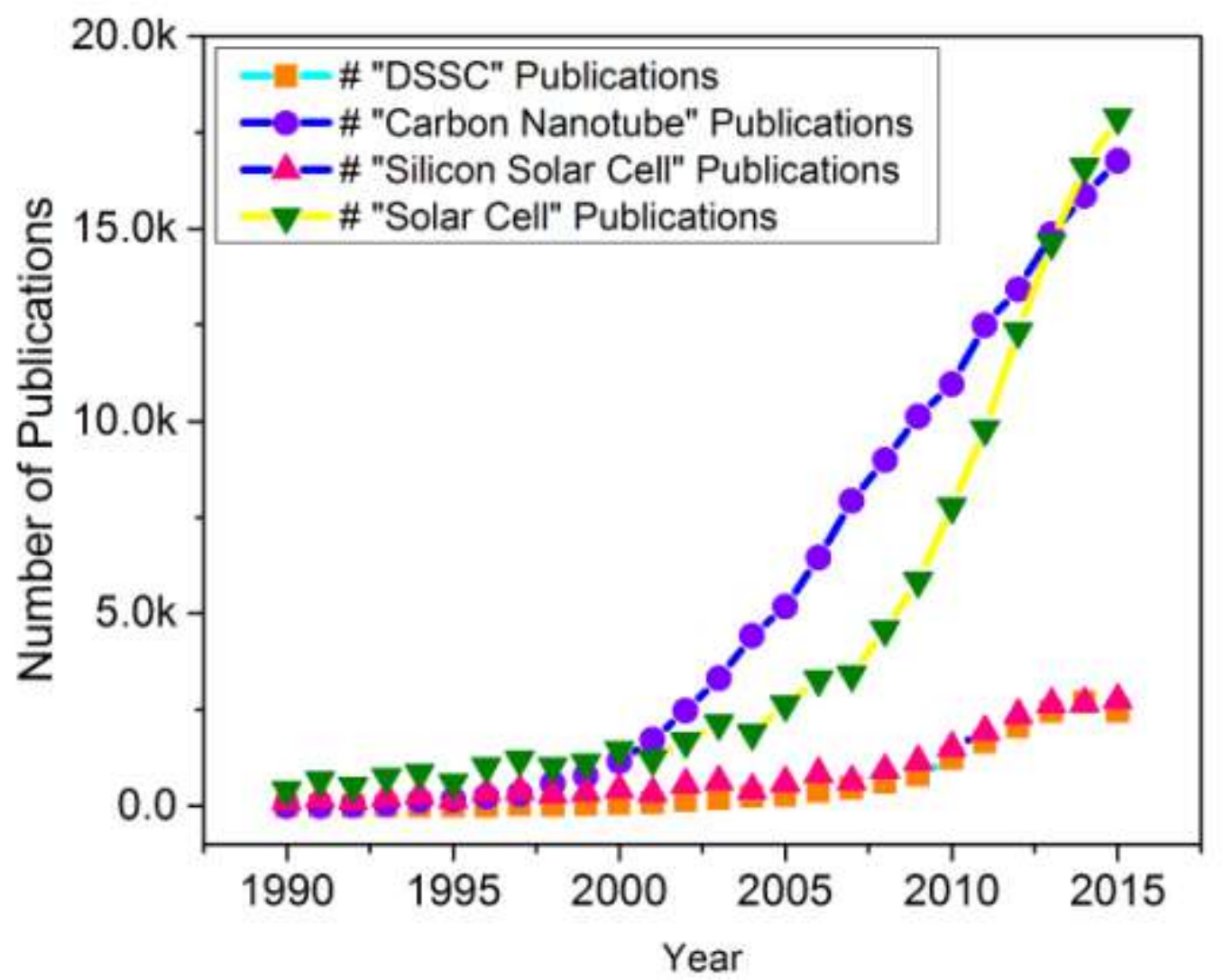

Figure 1. Research trends in carbon nanotube and dye sensitized solar cells.

DSSCs have five basic components: the organic dye which is excited by incident photons to produce electrons, the oxide layer into which the electrons from the dye excitation are introduced, the working electrode which lies behind the oxide layer and ultimately absorbs and transports the injected electrons, a redox mediator (often $\mathrm{I}^{-} / \mathrm{I}_{3}{ }^{-}$) that replaces the electrons injected from the dye, and a counter electrode (CE) that reduces the redox mediator / completes the circuit with the working electrode. The earliest dye sensitized solar cells utilized flat cell designs similar to modern crystalline / polycrystalline panels. These cells require a transparent conductive electrode to allow incident light to strike the oxide layer in the cell; transparent conductive oxides are often used for this purpose. Transparent conductive oxides (TCOs) have several major drawbacks however, the most apparent being their price (TCO production requires vacuum chambers and expensive input materials) and their rigidity / ill-suitability to deployment in solar cells that need to be flexible. Traditional flat DSSCs also characteristically utilize $\mathrm{I}^{-} / \mathrm{I}_{3}{ }^{-}$ 
redox mediators in a liquid electrolyte. Liquid electrolytes present multiple problems in that they can leak as the cell ages, make the solar cells prone to temperature fluctuation-induced wear, and make production of flexible DSSCs much more difficult as the electrolyte must be carefully contained. A schematic representation outlining the parts of a modern DSSC is presented below as Figure 2 for clarity. The location of the main functional components of the DSSC (working electrode, counter electrode, electrolyte, oxide layer) are visible, along with the relative location of sensitizers / quantum dots, which are seeing increasing use in novel DSSC designs.

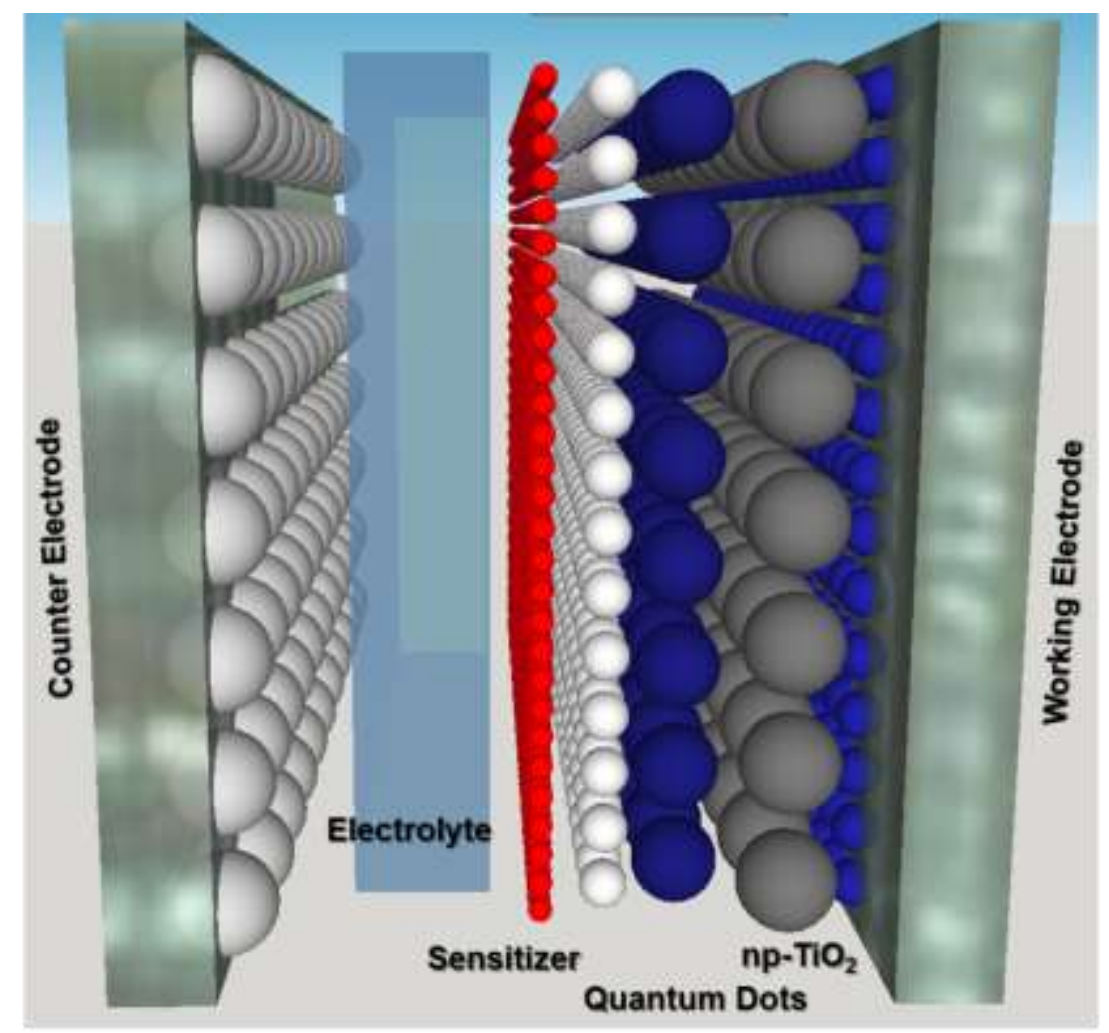

Figure 2. Schematic and sectional view of quantum dot-based DSSC. Original figure, cell design credit Uddin et al [15].

\subsection{Electrodes}

The optimization of electrode materials is very important for DSSC performance. The counter electrode must have high catalytic activity to reduce the redox mediator / push electrons back into the solar cell as efficiently as possible. Because the choice of counter electrode material can so strongly impact overall cell performance / conversion efficiency, a fair 
deal of research has been done towards optimizing the counter electrode. Platinum counter electrodes show high PCE; however, their cost would make large scale implementation of DSSCs prohibitively expensive. Nickel selenide and nickel sulfur films have been prepared and found to be as efficient as platinum-based counter electrodes, due to small interfacial resistance [16]. Working electrode materials must be resistant to oxidation or degradation with prolonged use; other materials have been evaluated as the counter electrode, with varying degrees of success $[17,18,19,20] . \mathrm{TiO}_{2}$ is often used as the oxide layer in cell construction, and optimization of its coating process has been an important topic of research. Jan Y. et al developed a two-step process consisting of first coating titanium with nanoporous- $\mathrm{TiO}_{2}$ which acts as a foundation layer for the major coating, microporous- $\mathrm{TiO}_{2}$. This process allowed for faster electron transport and higher surface area leading to higher exposure to the oxide layer by an increased number of dye molecules and quantum dots [21].

\subsection{Electrolytes}

A major hurdle in DSSC application is the use of a liquid electrolyte, which can leak, has temperature stability problems, is typically volatile (containing volatile organic compounds), and is also hazardous to human health and the environment. Servaites et al reported in 2012 that they'd prepared a solid electrolyte [10]. Conversion efficiency typically suffers when using a solid electrolyte, typically falling to around half that of conventional silicon cells. However, their further development will lead to practical advantages during DSSC fabrication, installation, and use [12]. Moreover, solid electrolytes will allow the fabrication of 3-D DSSCs (wire shaped) which will have uniform performance regardless of incident light angle due to their shape, a factor that is completely absent in flat conventional solar panels [22]. A disadvantage seen in most modern photovoltaic cells is that they require light to impact them at low incident angles / perpendicularly to the cell surface, or else cell conversion efficiency suffers. To overcome this, the inclusion of three dimensional structures on the surface of the panel has been explored. Three dimensional structures can potentially increase absorption and conversion rate, as well as improve cell response when light impacts at high incident angles [23]. A schematic representation of how such three-dimensional structures can be incorporated onto a DSSC surface is presented as Figure 3. Note that here the wire-shaped cell already has three- 
dimensional structure, while the addition of $\mathrm{TiO}_{2}$ tubes lends it an even larger surface area / provides more area for dye- $\mathrm{TiO}_{2}$ interaction.

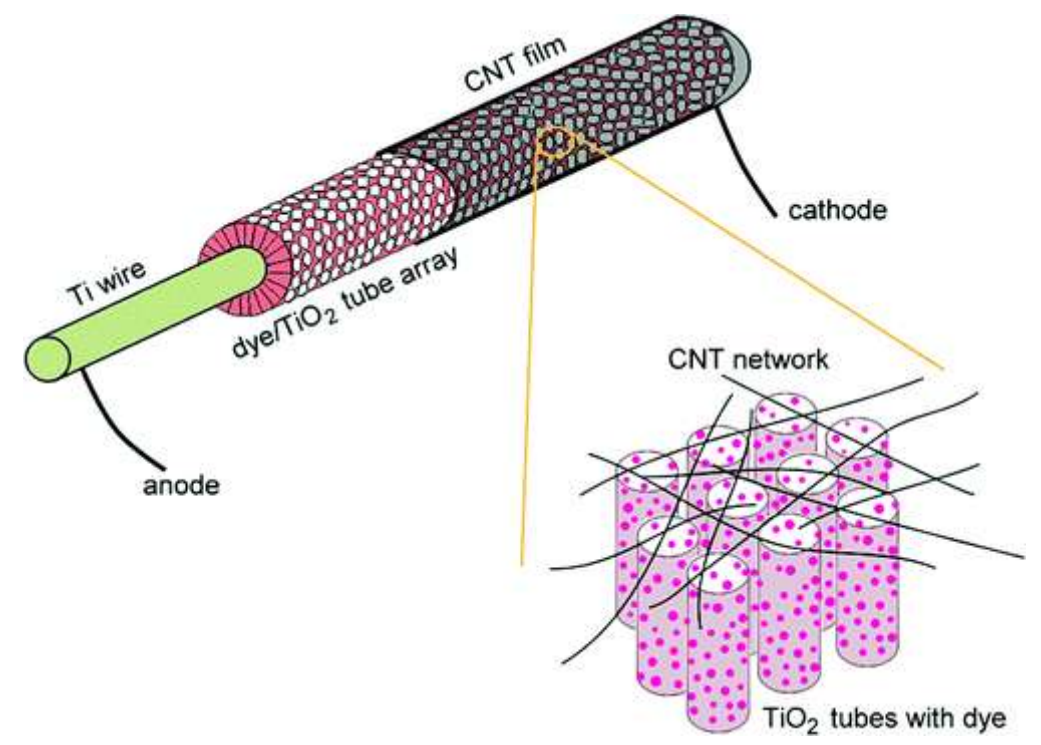

Figure 3. Schematic illustration of a wire shaped DSSC fabricated from a lightweight $\mathrm{Ti}_{-}-\mathrm{TiO}_{2}-\mathrm{Pt}$ structure [24].

\subsection{Sensitizers}

Conversion efficiency can also be improved by the inclusion of additional sensitizers in the solar cells. These sensitizers allow the cell to absorb and convert light over a greater wavelength range than can cells that lack sensitization, can allow for the injection of multiple electrons upon the absorption of a high-energy photon, and can improve electrode characteristics by providing a framework that lends the electrodes more active surface area. Nanocrystal quantum dots (QDs) have been used to improve cell characteristics. CdSe dots in particular have shown promise in decreasing electron recombination reactions and enhancing electron transfer processes, both of which positively affect the conversion efficiency of the solar cells [25]. Morphologically, these dots are non-spherical and have many edges and faces. Additionally, they are considered to be negatively charged due to molecules adsorbed on the surface. These quantum dots can allow for the conversion of incident light of short wavelength / high intensity 
to multiple injected electrons, as well as providing a scaffold for attachment to multiple dye molecules [26].

CdSe has a band gap of $1.7 \mathrm{eV}$ which lends it a wide absorption range of less than 730 nm. CdS quantum dots have a wider band gap of $2.25 \mathrm{eV}$, which lends them an absorption range of less than $550 \mathrm{~nm}$. CdSe quantum dots are less efficient than CdS because the conduction band edge is below that of $\mathrm{TiO}_{2}$. In order to take advantage of the absorption ranges of both $\mathrm{CdSe}$ and CdS quantum dots, merging of the QDs using a post-hydrothermal process has been studied. CdSe QDs have been estimated to have a molar extinction coefficient of 105 to $106 \mathrm{M}^{-1} \mathrm{~cm}^{-1}$, depending on the particle size and excitation wavelength [27,28]. These values are 10 to 100 times larger than those of organic dyes [29]. Using additional co-sensitizers with $\mathrm{CdSe} / \mathrm{CdS}$ quantum dots to improve IR absorbance has also been explored; when CdSe/CdS quantum dots are combined with dyes that have fair absorbance in the NIR region, a wider absorption range and thus better conversion efficiency is obtained [30]. These results are displayed in Figure 4; the NIR absorption peak of $\mathrm{ZnPc}$ is visible in Figure 3(a), and the enhancement effect of $\mathrm{ZnPc}$ on cell efficiency when combined with $\mathrm{CdS}$ can be seen in Figure 3(b).
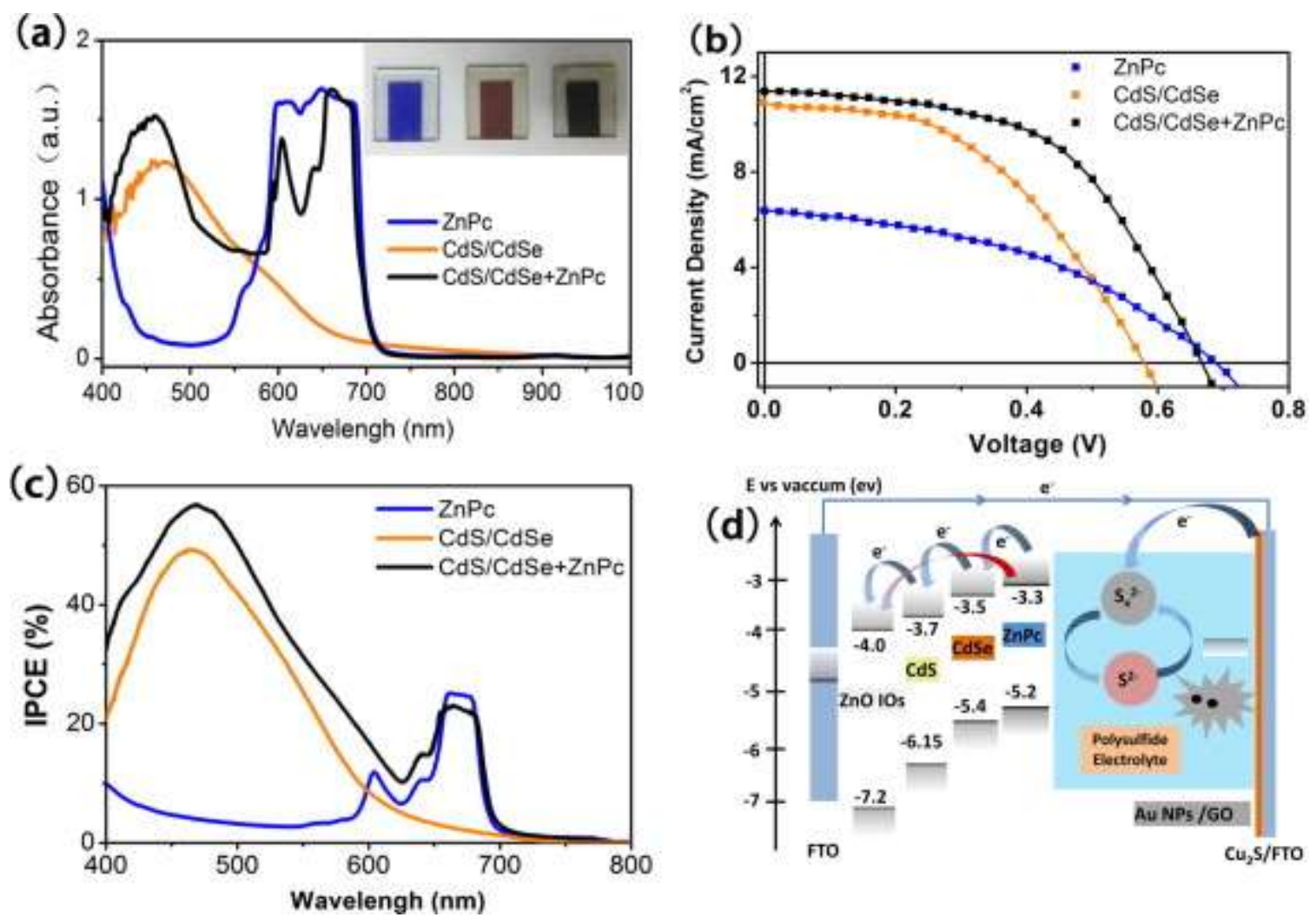
Figure 4. Sensitization effects of $\mathrm{CdS} / \mathrm{CdSe}$ quantum dots as well as the effects of a $\mathrm{ZnPc}$ cosensitizer [30].

Understanding of quantum dot / dye interaction with the $\mathrm{TiO}_{2}$ layer is important for continued optimization of DSSCs. The dye $\mathrm{N} 719 \mathrm{Ru}(\mathrm{II})$ adhered to $\mathrm{TiO}_{2}$ has been analyzed by high level DFT/TDDFT calculations [31]. It was shown that the theoretical absorption spectra for N719 had a wide energy absorption range, and had a maximum absorption deviation of less than $0.1 \mathrm{eV}$ over that range, which matches up with experimental results. This allowed Filippo and coworkers to assign ground-state electronic transitions, and it was found that the least optically active excited state was substantially influenced by the pi orbitals of the dye molecules interacting with the unoccupied $\mathrm{TiO}_{2}$ orbitals. Stronger coupling between the dye and $\mathrm{TiO}_{2}$ was also calculated for higher transitions. An ultrafast, almost instantaneous, electron injection was predicted, on the basis of the strong coupling and match between the visible absorption spectrum and density of unoccupied $\mathrm{TiO}_{2}$ states. This instantaneous injection corresponded to an excitation of the dye delocalized within the semiconductor, and the timings of electron injections are mainly controlled by electron dephasing in the semiconductor. The continuing research into quantum dots shows great promise; their high photon absorption coefficient, multiple exciton generation effects, and tenability allow for them to be used in a wide variety of applications including dye sensitized solar cells.

\section{Advanced Materials for DSSCs}

Optimization of the DSSC components discussed above in sections 2.1-2.3 is vital to improving overall DSSC performance, and a lot of effort has gone into improving the material characteristics of the individual DSSC components. Some of these improvements (such as the incorporation of carbon nano tubes and other nanostructured materials) are the result of materials science research with many applications outside the field of DSSC's, while other research is more narrowly focused on improving DSSC characteristics directly.

\subsection{Carbon Materials}

Research into carbon-based materials has made extensive progress within just the past decade [32]. From the time when carbon nanotubes were first discovered by lijima et al in 1991, they have found a variety of applications in both industrial and scientific settings, due to their 
striking properties $[33,34,35,36]$. These properties depend on a variety of factors, including diameter, length, defects, concentration, number of walls, and the synthesis method used to create them. Because they can take on a wide range of physical and chemical properties, they've been used for applications as diverse as high-strength composites, batteries, supercapacitors, solar cells, sensors, actuators, drug delivery systems, electronic devices, transparent conducting films (TCFs), and catalysts.

Carbon nanotubes are allotropes of carbon, consisting of cylindrical structures walled by one or more layers of graphene, with open or closed ends. They can be classified as single walled carbon nanotubes (SWCNTs), double walled carbon nanotubes (DWCNTs), or multi-walled carbon nanotubes (MWCNTs) depending on the number of walls. The most widely studied of the three are single walled carbon nanotubes and multi walled carbon nanotubes; SWCNTs consist of only a single graphene sheet, while MWCNTs have multiple sheets with an interlayer distance of 3.4 angstroms, which is similar to the interlayer spacing of graphite. The characteristic diameters of SWCNTs and MWCNTs are 1-2 nm and 3-30 nm respectively, and the tubes tend to be curved rather than straight [37]. The solubility of carbon nanotubes can be increased by "grafting" electrolytes onto their walls. Highly water soluble MWCNTs were synthesized this way by Han et al [38]. Due to the electrostatic charge-assisted deposition method, the thin films were uniform over a large area and maintained the intertwined structure of the exfoliated MWCNTs. CNTs are applicable as both working and counter electrodes, and a cell design utilizing CNTs as both electrodes is shown below as Figure 5. With CNTs acting as both electrodes, expensive / inflexible electrode materials such as platinum can be eliminated. 
a)

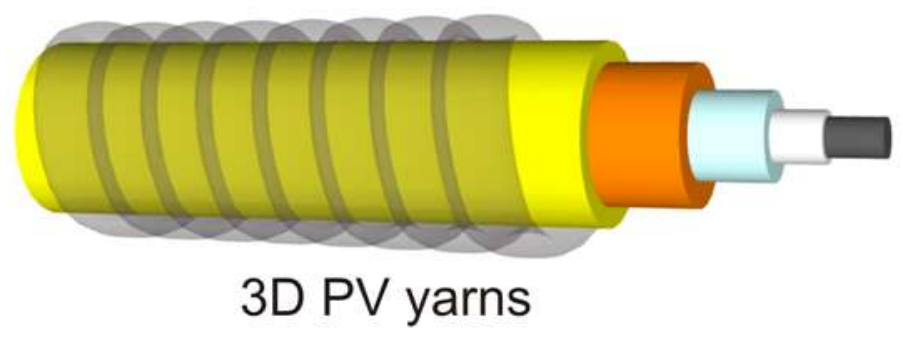

b)

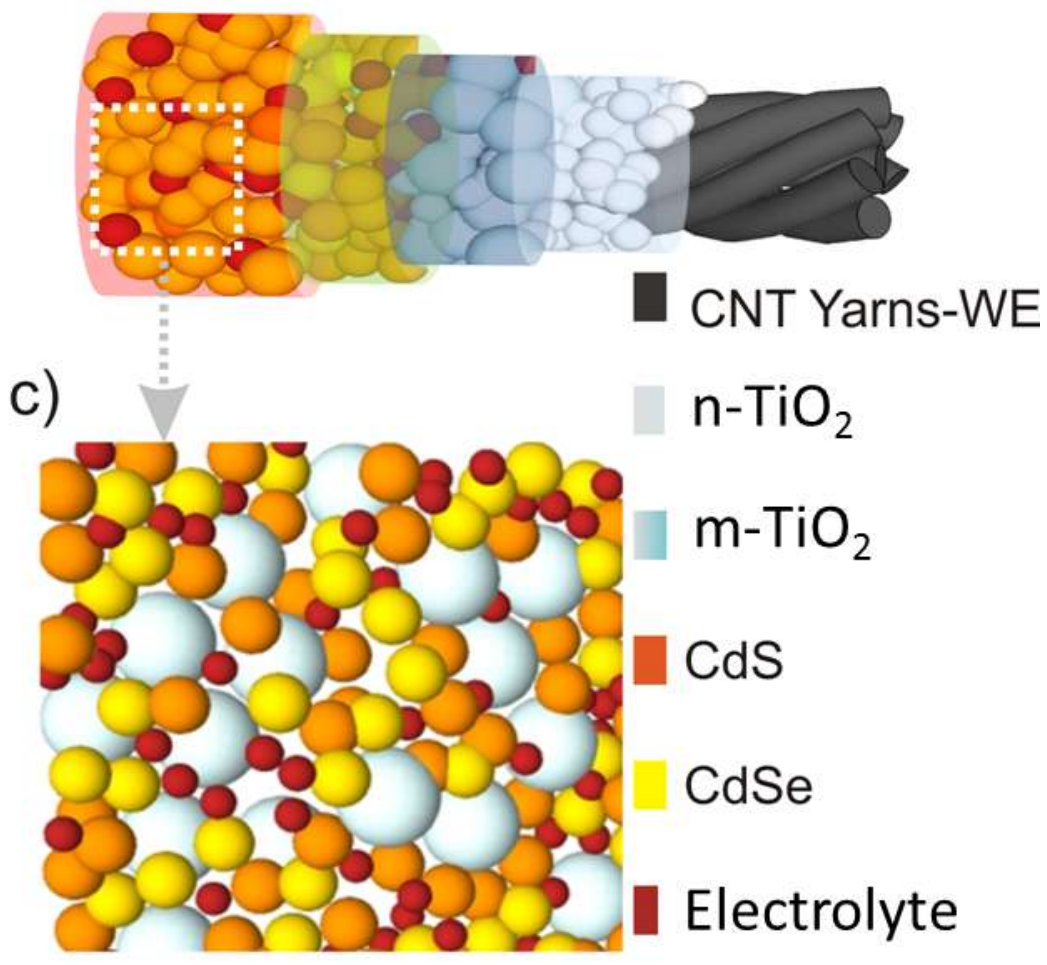

d)

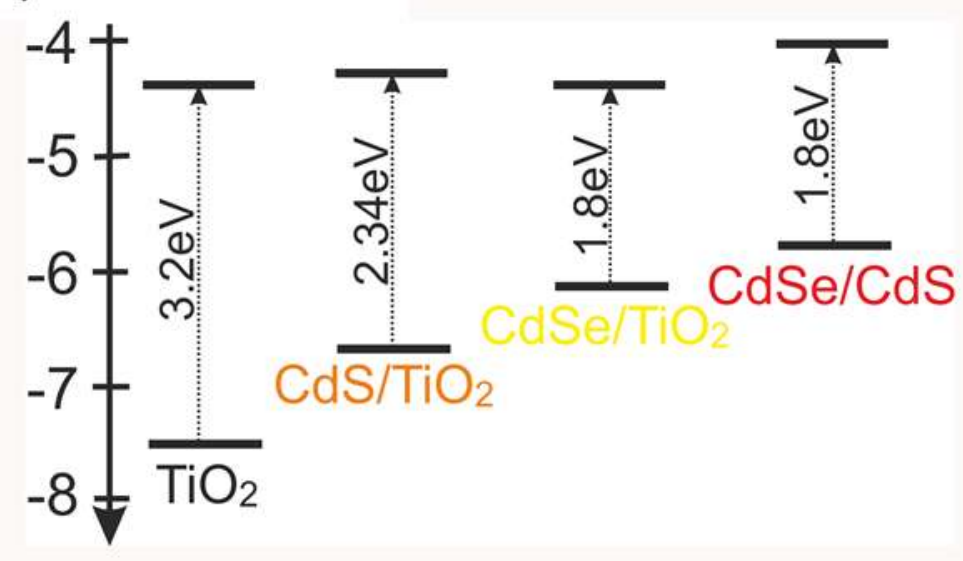


Figure 5. Schematic of a flexible wire-type DSSC constructed with carbon nanotube yarn serving as both the working and counter electrodes [15].

High aspect ratio (length:diameter ratio) CNTs have been fabricated with tunable lengths from nanometers up to several centimeters. Carbon nanotubes also have high electrochemical activity and an interactive surface; unlike platinum, gold, or silver. Transparent conductive oxides are typically prone to cracking and are very costly; the fluorine doped tin oxide (FTO) glass used in DSSCs contributes $60 \%$ of the total cost of their manufacture. Kamat et al and Kongkanand et al reported that incorporating CNTs into the $\mathrm{TiO}_{2}$ structure of DSSCs could help transport the photo-generated electrons towards the working electrode [26,39]. In 2004 manufactured SWCNT films were able to achieve $0.15 \%$ conversion efficiency in solar cells. The $\mathrm{TiO}_{2}$ was laid down post-deposition of the conductive SWCNT film on the carbon fiber electrode. The assembled $\mathrm{SWCNT}-\mathrm{TiO}_{2}$ device produced roughly double the photocurrent density of $\mathrm{TiO}_{2}$ alone, of equal morphological properties. SWCNTs can also have an electrocatalytic effect as demonstrated by Kongkanand et al, as it was found that SWCNTs significantly increased the incident photon conversion efficiency from $7.36 \%$ to $16 \%$ [38]. This dramatic increase indicates that SWCNTs play an important role in both charge collection in the electrodes and charge transport in the oxide films. The high aspect ratio and large surface area of CNTs have been shown to be favorable to exciton dissociation and charge carrier transport [40]. Low diameter nanotubes have larger surface areas which allow maximum interaction with the matrix; however, the diameter needs to be large enough to maximize loading of the nanotubes. The optimum diameter and length have been predicted by analysis of the optical properties of SWCNTs [41]. Several SWCNTs of different diameters were fabricated via laser ablation, and then studied via optical absorption spectroscopy, high-resolution electron energy loss transmission spectroscopy, and tight-binding calculations. Liu X. et al were able to accurately define the average diameter and diameter distribution of the nanotube samples studied [42]. A detailed analysis of the optical absorption spectra also allowed insight to be gained concerning the possible existence of a chirality dependence during the SWCNT formation process. The best agreement between the simulated and experimental spectra is observed when the chiral angle of the nanotubes is restricted to within $15^{\circ}$ of the armchair axis. The mean diameter and length 
distributions that resulted from the simulation were in very good agreement with the values derived from other bulk-sensitive methods such as electron diffraction, X-ray diffraction, and Raman scattering [42].

Post-chemical treatment of CNT fibers with intramolecular cross-dehydrogenative coupling (ICDC) reactions dramatically improves electrical conductivity and mechanical tensile strength [42]. The method used in the above study effectively linked the carbon nanotubes chemically using $\mathrm{FeCl}_{3}$, so that van der Waals interactions were no longer the only force between them. After this treatment, the electrical conductivity of the CNT yarn was $3500 \mathrm{~S} / \mathrm{cm}$, which was almost $200 \%$ greater than the conductivity of the neat CNT yarn [43]. Ni et al demonstrated another DSSC efficiency increase using functionalized SWCNTs decorated with CdSe/ZnS coreshell colloidal quantum dots incorporated into different copolymers [44]. The results showed that the use of quantum dots increased the efficiency of non-quantized solar cells by $30 \%$ [44]. Dye sensitized solar cells that are not quantized tend to show a conversion energy factor that is slightly below $10 \%$ [45]. Therefore, the power conversion efficiency associated with the use of functionalized CNTs is likely around $11-13 \%$.

The use of carbon nanotubes also promises to further the development of a solid electrolyte, as well as contribute to overall cell elasticity. Carbon nanotubes can be used to create carbon nano-yarn which itself can serve as a counter electrode in DSSCs, and they can be incorporated into more traditional metal-based electrode DSSCs. CNTs also provide a large surface area and promote the transport of electrons to the electrode surfaces by decreasing the transfer resistance of electrons [46]. Conventional DSSCs with CNTs incorporated into them exhibited over $12 \%$ conversion efficiency [47]. Carbon nanotubes can be used as a substrate to grow branched $\mathrm{TiO}_{2}$ crystals which improve light scattering / dye loading, and allow for more effective electron collection by increasing the surface area of the oxide layer [48]. This $\mathrm{CNT} / \mathrm{TiO}_{2}$ nanorod system shows great application for flexible DSSCs (Figure 6), with conversion efficiencies of up to $4.18 \%$ [48]. 


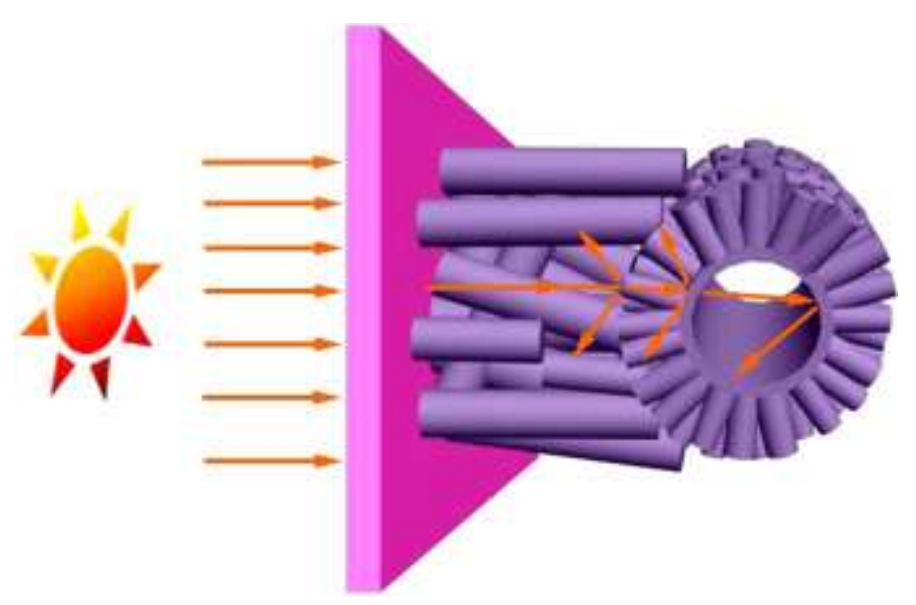

Figure 6. Schematic of the $\mathrm{CNT} / \mathrm{TiO}_{2}$ nanorod system and the effect that is has on light scattering. [48].

CNTs can also be used to fabricate flexible DSSC counter electrodes via coating onto polyester fabric, potentially opening up textile-based applications for DSSCs [49]. A facile tape casting method was used to deposit the CNTs, which is economical compared to more advanced coating techniques. The MWCNT coated fabric electrodes had low surface resistances, and demonstrated $5.69 \%$ conversion efficiency when employed as flexible DSSC electrodes. CNTs deployed in this way exhibit high sheet conductivity, low charge transfer resistance, and excellent catalytic activity [49]. The flexible polyester substrate employed also showed stable conductivity over repetitive bending cycles, good polymer gel electrolyte retention due to its hydrophobic nature, and strong mechanical adhesion of the CNTs [49]. Such coated CNTs open the door for flexible fabric-integrated DSSCs. Enzyme-based dispersion of CNT's onto fabric could further progress towards integrated fabric-based DSSC's, and a variety of methods have been developed to disperse / adhere them onto fabric surfaces. Figure 7 shows polyester fabric coated with CNTs to form a conductive, textile-based electrode that can be used in the fabrication of DSSC's. The differing CNT morphologies obtained when dispersing with different enzymes are also apparent, suggesting that CNT morphology can be further tuned to enhance cell performance. 


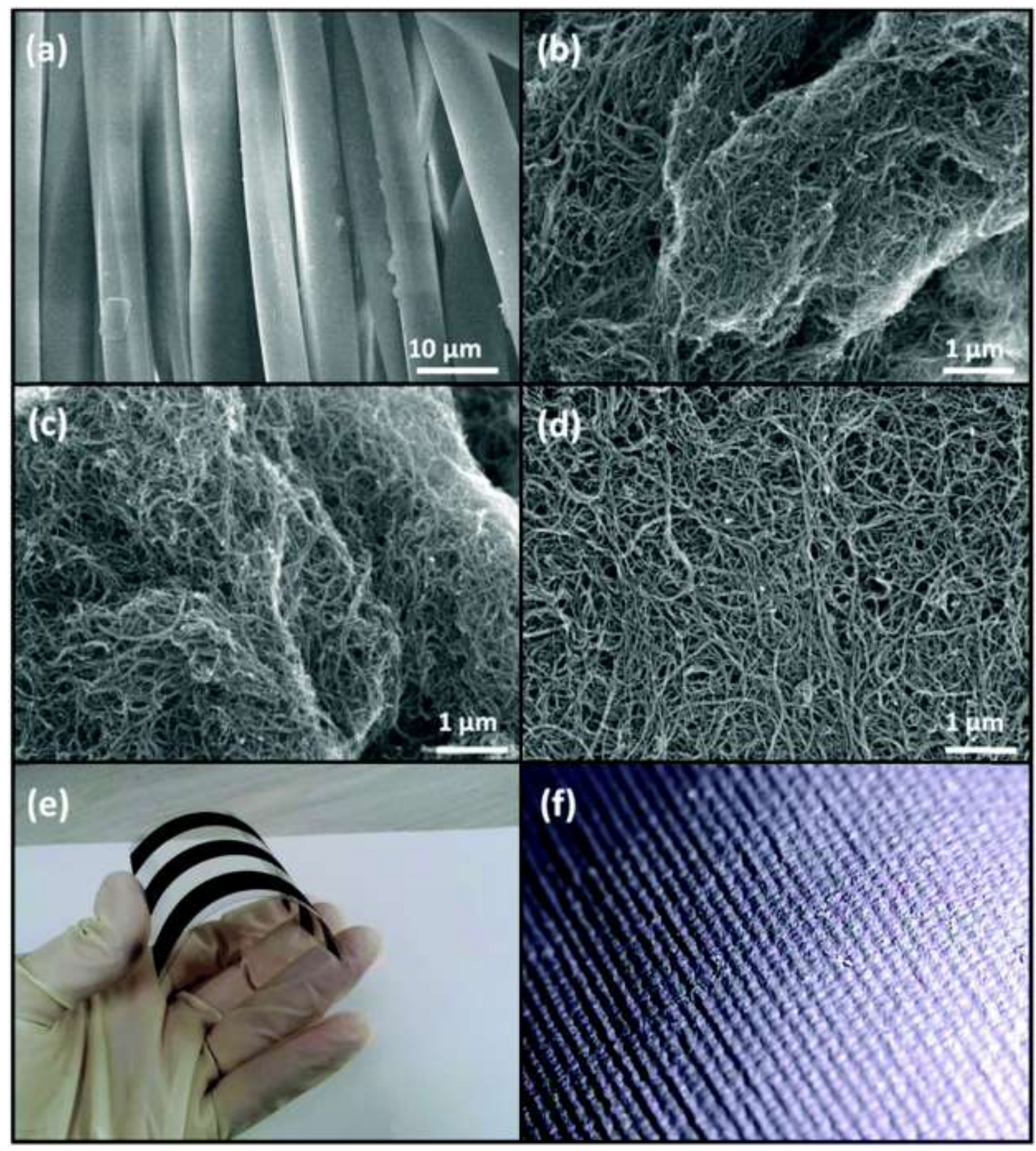

Figure 7. FE-SEM images of (a) Neat polyester fabric. (b-d) MWCNT dispersed with a variety of enzymes and deposited onto polyester fabric. (e) An image of the MWCNT coated film. (f) Micro graph of MWCNT coated polyester fabric electrode [49].

The use of carbon nanotubes as DSSC counter electrodes has been explored given their high surface area and distinctive electrical, optical, physical, chemical, and catalytic properties. 
However, conventional flat DSSC cells with fluorine doped tin oxide (FTO) glass are inflexible and thick. In order to resolve these two drawbacks, a flexible wire-shaped DSSC that possesses high flexibility and small size was suggested to replace conventional devices with similar functions. These metal-supported wire-shaped flexible DSSCs have seen rapid development and recently achieved an efficiency greater than $8 \%$ using liquid electrolytes [18]. An example solid state metal supported DSSC is shown in Figure 8. The uniform deposition of the $\mathrm{TiO}_{2}$ layer on the titanium wire along with the ease of deposition through an anodization process is one of the major advantages of using a metal working electrode. 


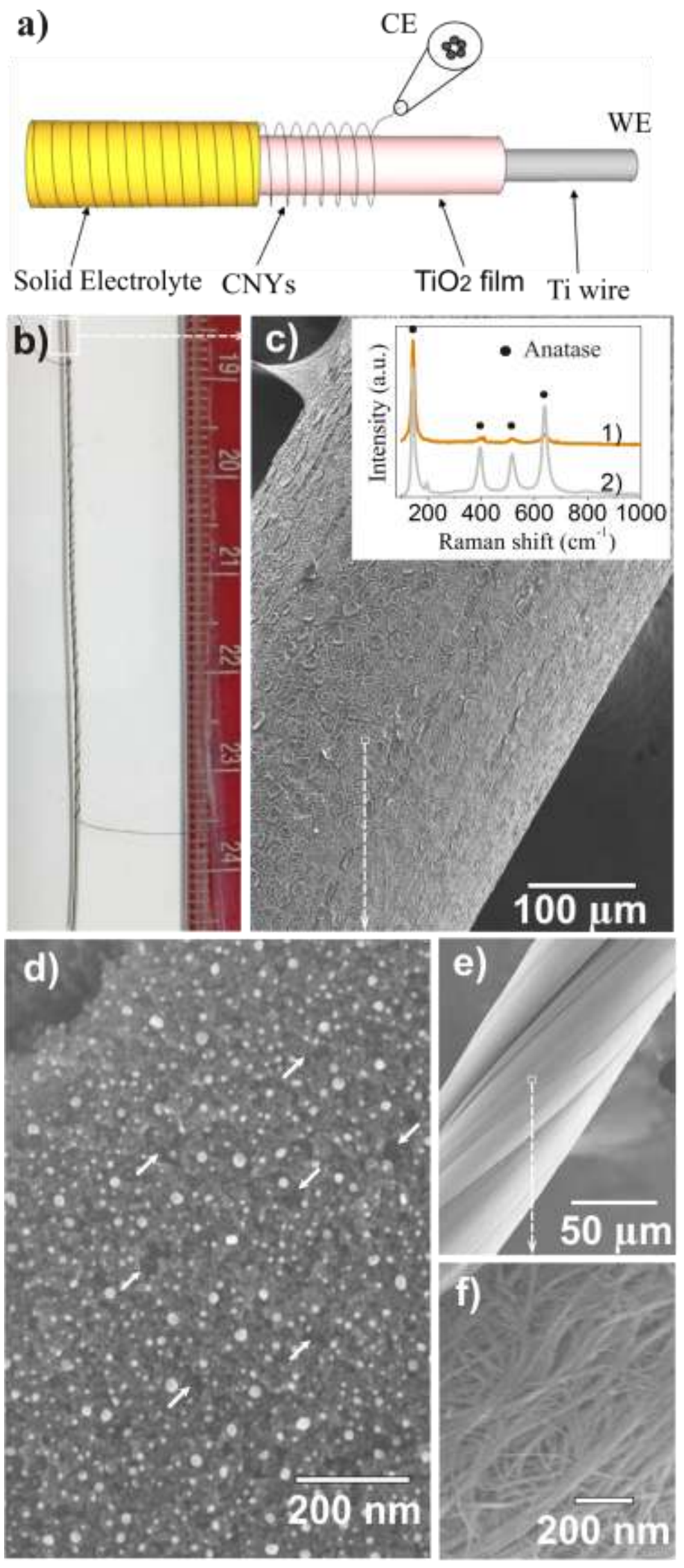


Figure 8. Carbon nano-yarn deployed as a DSSC counter electrode. (a) Schema of the flexible DSSC's structure, (b) Enlarged view of $\mathrm{TiO}_{2}$ layer, (c) SEM image of $\mathrm{TiO}_{2}$-coated Ti wire (WE), (d) Enlarged view of $\mathrm{TiO}_{2}$ layer, (e) SEM image of CNY (CE), (f) enlarged view of CNTs composite CNY surface

CNTs have also been platinized and verified to be efficient in DSSCs as counter electrodes [24, 50]. The platinized CNT counter electrodes gather electrons and catalyze the regeneration of the iodide redox mediator [19]. The contact between the CNTs and electrolyte is responsible for mediating charge transfer and overall cell performance. Because of this, carbonbased electrodes and the redox electrolytes have been optimized through various research methods [24]. With the recent advancements into improving efficiency and cutting costs of DSSCs, they will be commercially viable in the near future. Novel nanostructured composite fibers based on graphene and CNTs have been developed into materials with high tensile strength, electrical conductivity, and electrocatalytic activity [51]. Many applications exist for these fibers, and they have been used to fabricate wire shaped DSSCs and wire shaped supercapacitors. The wire shaped DSSC shows a maximum energy conversion efficiency of $8.50 \%$ and the supercapacitors exhibited high specific capacitance.

Carbon fibers show a great deal of promise in DSSC applications due to their interactive surfaces and conductivity. Additionally, corrosion of the metallic working electrode is a common problem in DSSCs, which has led to the exploration of CNT wires for electrode materials [52]. Chen et al reported $2.94 \%$ conversion efficiency using a CNT wire coated with dye-filled $\mathrm{TiO}_{2}$ nanoparticles [30]. Carbon fibers make an ideal substrate for a variety of DSSC applications. A schematic of a DSSC utilizing two carbon fibers as electrodes as a liquid electrolyte is shown in Figure 9; intertwining carbon fibers around each other allows for a flexible rope-like structure to be constructed, lowering cell volume. 
a

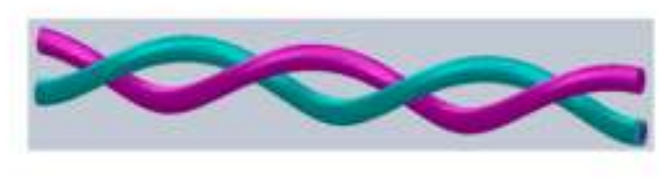

b

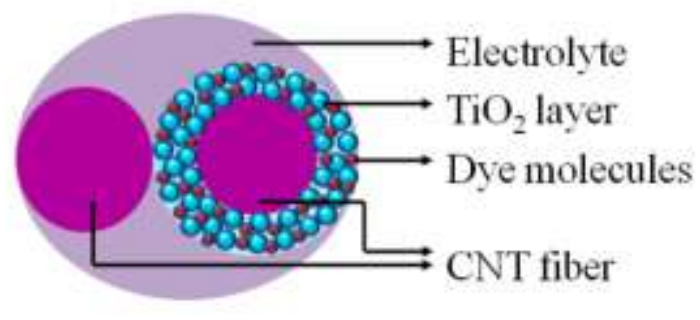

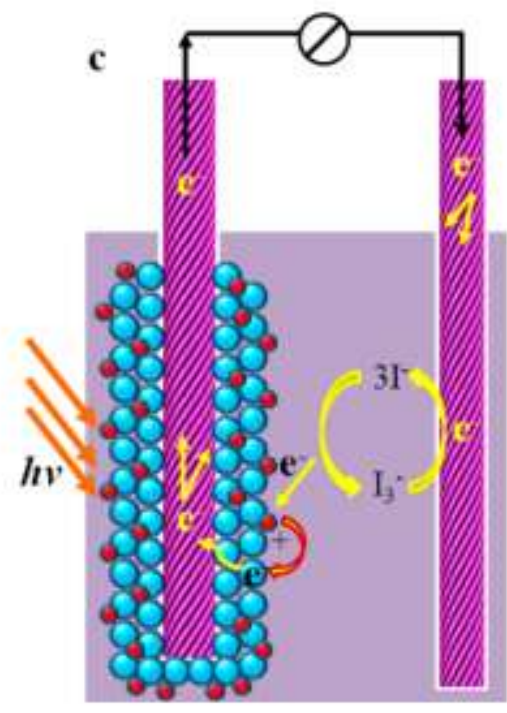

Figure 9. Schematic illustration of a wire shaped DSSC fabricated from two CNT fibers. (a) Two CNT fibers twined into a cell. (b) Top view of the cell. (c) Working mechanism [52].

Peng H. et al evaluated carbon nanotubes, core-sheath CNT / reduced graphene oxide nanoribbon, CNT/reduced graphene oxide composite, and reduced graphene oxide fibers, and found that the highest energy conversion efficiency of 5.64\% was produced from CNT/RGONR carbon fiber counter electrodes [51]. Optimization of a carbon based counter electrode is very important for continued wire-shaped flexible DSSC development. Peng $H$. et al also demonstrated that incorporation of Pt nanoparticles into the core sheath nano-structures fiber could improve energy conversion efficiency to $6.83 \%$, which is greater than half the efficiency of conventional non-flexible DSSCs which incorporate CNTs. Carbon nano-felt also shows promise as a potential cost-effective DSSC counter electrode materials, and displayed energy conversion efficiencies of up to $6.94 \%$ when used in a conventional DSSC system [53]. Carbon fibers are also ideal for use as counter electrode in cells based on metallic working electrodes. Because carbon fiber is flexible, it can be wound well around metal wires as demonstrated in Figure 10. 


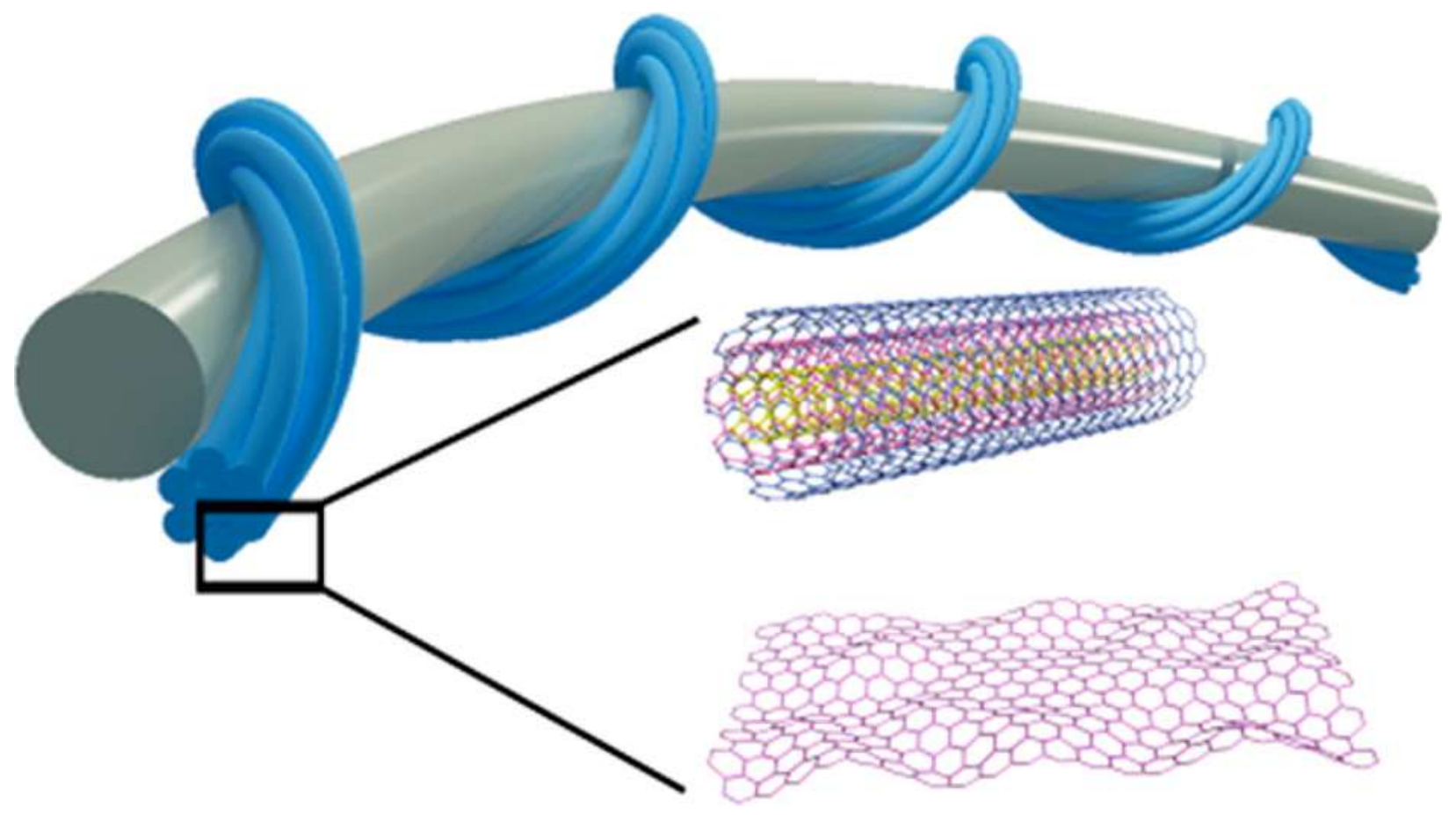

Figure 10. Schematic representation of a carbon fiber / Ti DSSC [52].

Carbon fiber can also provide a substrate for growing nanocrystals for application in DSSCs, much like CNTs as discussed earlier. Grynko et al successfully demonstrated the growth of radially oriented $\mathrm{CdS}$ nanowire crystals around a carbon fiber which served as the core electrode [54]. On top of this dye/ polymer layers were deposited, and a core-shell photovoltaic structure was assembled on the micro scale. These cells showed very low power conversion efficiencies $(0.015 \%$ being the best achieved); however, single carbon fiber solar cells show great promise in textile-based applications as they are extremely small and resistant to flexinginduced wear [54]. Chen L. et al explored the one-step growth of $\mathrm{CoNi}_{2} \mathrm{~S}_{4}$ nanoribbon and nanorod on carbon fibers for use as DSSC counter electrodes. $\mathrm{CoNi}_{2} \mathrm{~S}_{4}$ nanorod on carbon fiber produced a conversion efficiency of $7.03 \%$, which is comparable or even superior to Pt wire counter electrodes [55]. Chen L. et al also explored the growth of porous titanium nitride nanoplates on carbon fibers, and obtained an even higher conversion efficiency of $7.20 \%$. Nitrides, and other inorganic metal compounds such as carbides, sulfides, and oxides of Ti, W, and Co have shown promise in traditional planar type DSSCs. Thus, progressive investigations towards new and facile methods of coating these inorganic metal compounds onto highly curved surface morphologies of carbon nanofibers will potentially lead to platinum free / inexpensive 
fiber type DSSCs [55]. A schematic of these sensitizers coated on carbon fibers is shown in Figure 11; they are coated directly on the surface of the counter electrode.

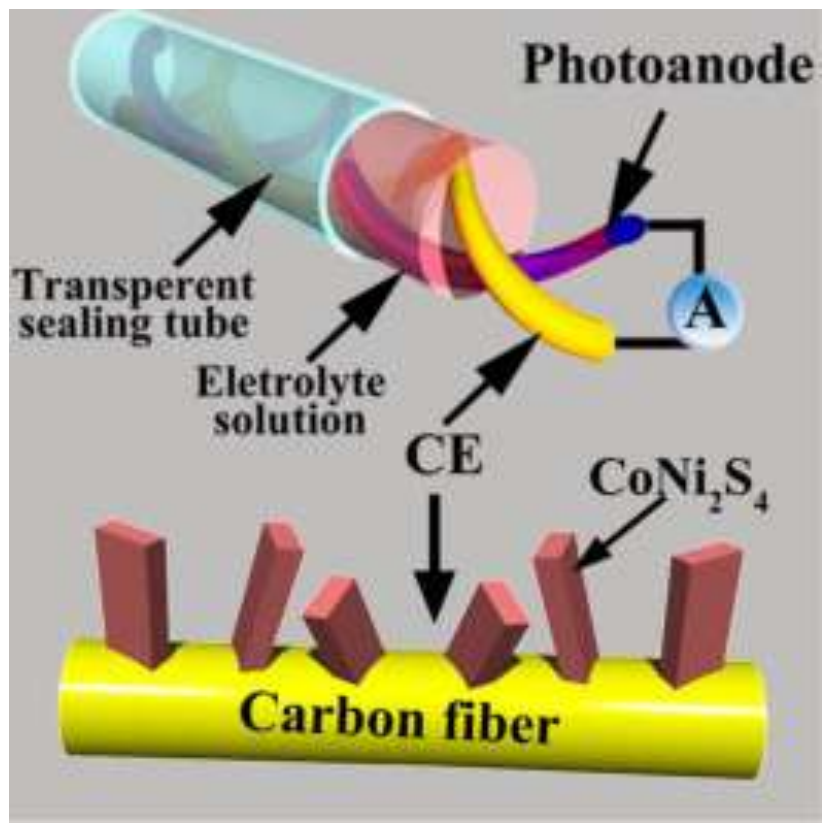

Figure 11. Schematic representation of $\mathrm{CoNi}_{2} \mathrm{~S}_{4}$ on carbon fiber [55].

\subsection{Inorganic Materials}

Inorganic materials have also been explored to create more efficient and versatile DSSCs. Liang et al reported the fabrication of $\mathrm{TiO}_{2} / \mathrm{Pt}$ flexible fiber type DSSCs which had a 5.4\% ECF [56]. These cells were bendable; however, they showed decreased ECF with repeated reshaping, which compares negatively with carbon-based DSSCs which show minimal loss of ECF after reshaping. Additionally, these cells use platinum, making them expensive to produce. Improving the efficiency of fiber-shaped DSSCs (FDSSCs), and the use of $\mathrm{SnO}_{2}$ nanoparticles to sensitize FDSSCs, have been explored. Peng M. et al used thermal calcination of tin tetraisopropoxide solution on titanium wires, and found that the cells had PCEs of around 5.8\%, which could increase when a diffuse light reflector was placed beneath the cell [57]. Fabrication methods other than calcination of tetraisopropoxide were also presented, but they require advanced fabrication techniques which counteract the benefit of the PCE increase. Waveguide fiber type DSSCs have potential applications (such as conversion of light passing through windows into usable energy), and have been explored in some detail. Peng M. et al report the production of lightweight waveguide fiber dye-sensitized solar cells integrated with luminescent solar 
concentrators, which showed an enhanced conversion factor of $5.7 \%$, and demonstrated significant absorption of light over 0-80 and 100-180 degree angles [58]. They noted that the cells showed reasonable performance when directly exposed to sunlight as well as under shaded conditions. The application of these cells to domestic and commercial windows could help offset power costs. A schematic of a waveguide fiber-type DSSC is shown below as Figure 12 (c), along with an SEM image of the porous $\mathrm{TiO}_{2}$ surface. Note that the packaging tube differentiates this cell type from other similar cell designs.
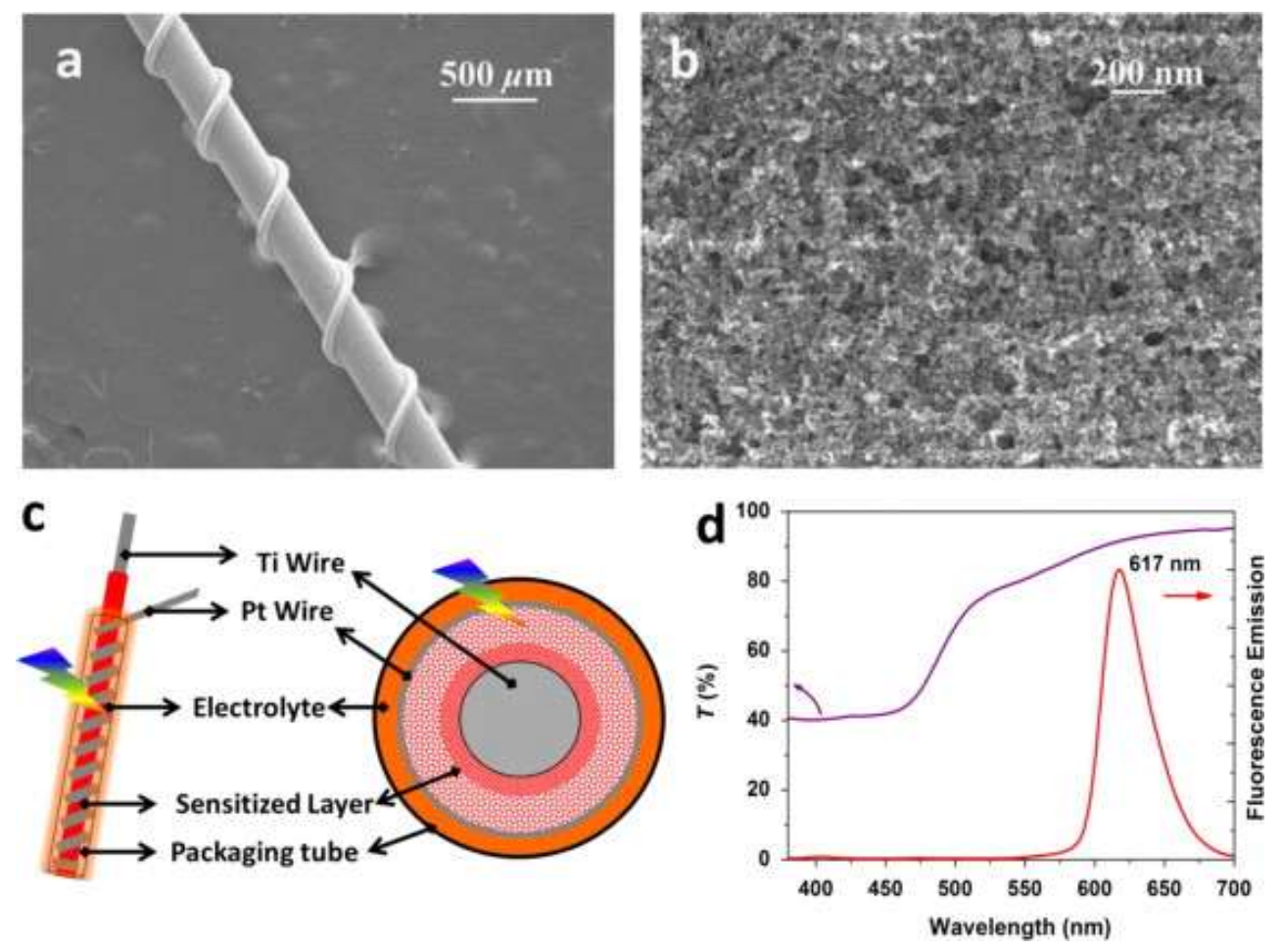

Figure 12. Schematic and experimental results of the waveguide fiber-type DSSCs [58]. (a) Fiber electrode with twisted Pt wire as the counter electrode; (b) SEM image taken for porous surface of a dye-sensitized $\mathrm{TiO}_{2}$ nanocrystal layer $(\sim 18 \mu \mathrm{m})$; (c) schematic diagram showing the front and cross-sectional views of a typical FDSC; and (d) transmission spectrum of electrolyte and fluorescence emission (excited at $365 \mathrm{~nm}$ ) of the red LSC.

DSSCs based on $\mathrm{TiO}_{2}$ micron-core arrays with novel multilayered structured photoanodes have been constructed [59]. The cells achieved a max PCE of 8.07\%, which was the highest value reported for a FDSSC at the time the paper was published. In addition to this an important property was high flexibility of the fiber; it retained $96.6 \%$ of its initial conversion 
efficiency after being bent 100 times, and the minimum bending radius of the photoanode was reported as $0.45 \mathrm{~mm}$ [59]. It is also worth noting that photoactive $\mathrm{TiO}_{2}$ films incorporated into cellulosic fibers demonstrate antimicrobial properties, which opens the door to further textile based applications [60].

$\mathrm{Li} \mathrm{Z}$. et al reported the electrophoretic deposition of graphene- $\mathrm{TiO}_{2}$ hierarchical spheres on Ti thread [61]. The deposition technique enables film thickness to be finely tailored, and they obtained conversion efficiencies of $3.26 \%$ after treatment with $\mathrm{TiCl}_{4}$ to improve connectivity between the film particles. Additionally, the incorporation of multiple spherical layers enables better light trapping and reflection between the spheres, a technique that can be adapted to improve conversion efficiencies with other types of photoanodes [61]. A 3D network composed of titania on Ti foil was constructed by Rui Y. et al using a simple fabrication process, and it reached a maximum conversion efficiency of $4.98 \%$ and retained $97.3 \%$ of its initial conversion efficiency after twenty consecutive bends [62].

\subsection{Polymer Based DSSCs}

Conductive polymer based substrates also show promising applications in DSSCs. Malyukov et al developed a method for selectively sintering $\mathrm{TiO}_{2}$ on a plastic conductive substrate [63]. The laser sintering process can potentially lead to simple industrial production of plastic-based DSSCs. Hou et al synthesized flexible and ultrathin polyaniline nanoribbons which, when employed as a DSSC counter electrode, produced conversion efficiencies of up to $7.23 \%$ (97.4\% of the conversion efficiency produced by platinum based counter electrodes) [64]. Gerosa M. et al tested three different polymer / metal mesh based DSSCs utilizing UV crosslinked polymeric electrolytes, and found reasonable efficiency [65]. A variety of the cell designs tested by Gerosa et al are shown in Figure 13, with the cells generally progressing from least complex to most complex. 

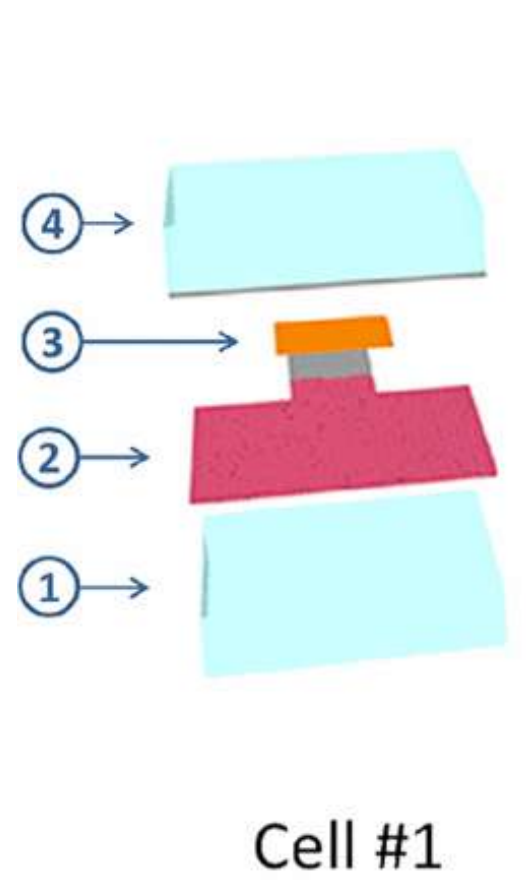

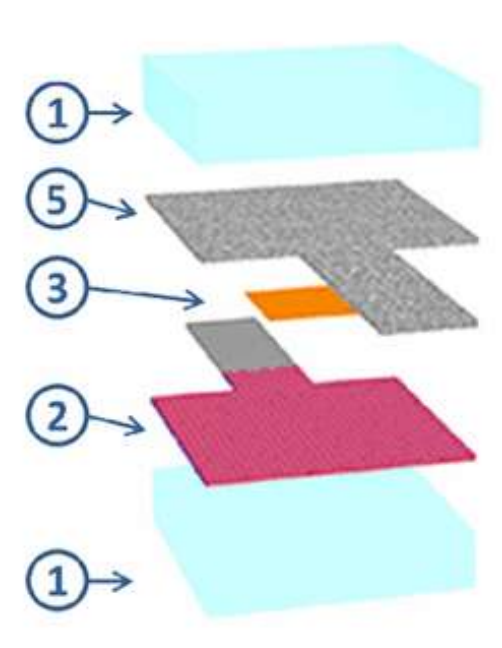

(a)

Cell \#2

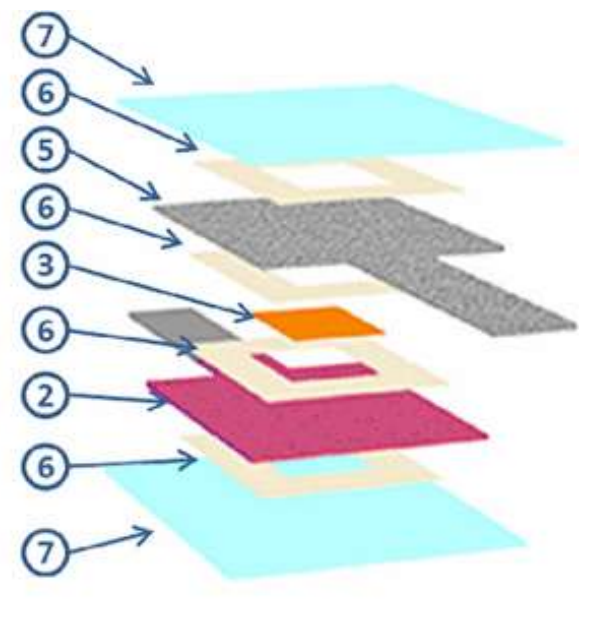

Cell \#3

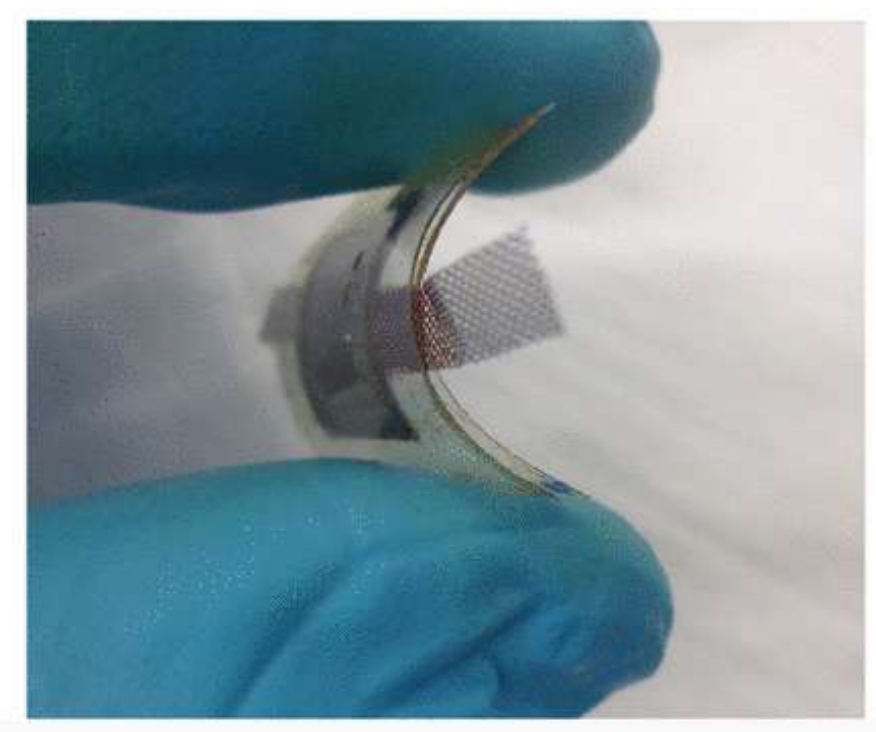

(b)

Figure 13. (a) Three-dimensional scheme of the three cell architectures. Components: glass support (1), Ti grid with $\mathrm{TiO}_{2}$ and $\mathrm{N} 719$ (2), PEM (3), Pt-coated FTO/glass (4), Pt-coated Ti grid (5), Meltonix film (6), PET foil (7). (b) Final device (cell \#3) [65].

\subsection{Fiber Based DSSCs}

Fabric-type DSSCs have gained a fair amount of attention, and several studies into manufacturing DSSCs directly on the surface of a fiber have been done. Xu Q. et al successfully 
coated polypyrrole directly onto nickel coated cotton fabric, and when a DSSC was constructed with this fabric-based counter electrode conversion efficiencies of up to $3.83 \%$ were obtained [66]. Opwis K. et al prepared a DSSC based on heat resistant glass fibers, and obtained a conversion efficiency of $1.8 \%$ [67]. The fabricated device was lightweight, flexible, large area, and maintained photovoltaic activity over the course of seven weeks. Sahito I. A. et al deposited graphene onto cotton fabric and successfully produced a counter electrode that obtained conversion efficiencies of up to $6.93 \%$ [68]. Furthermore, Pan S. et al have explored stacked textile based (consisting of woven carbon fibers and titanium mesh) DSSCs which achieved a conversion efficiency of $3.67 \%$ which was entirely independent of the incident angle of the light [69]. A schematic representation of this process / the final product is presented as Figure 14.

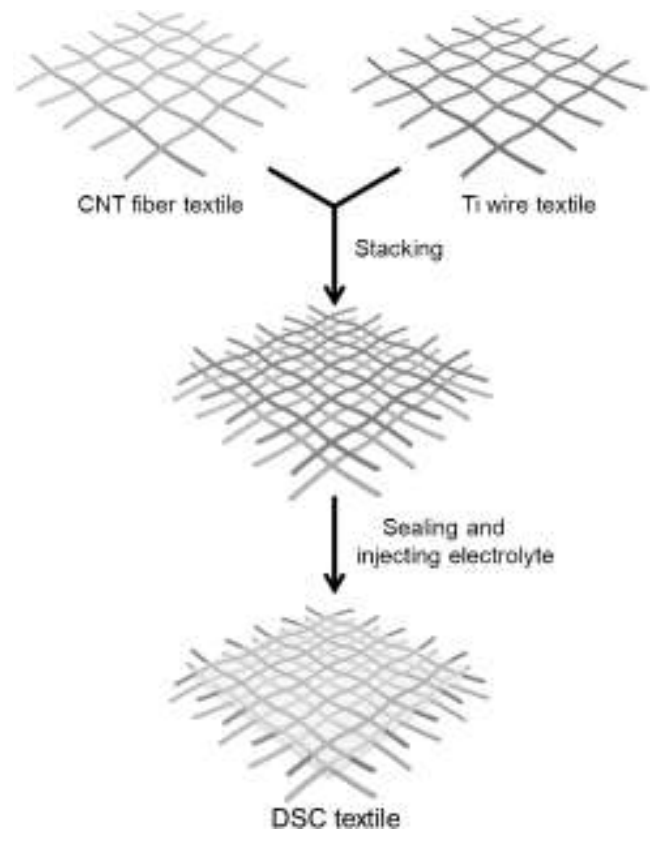

Figure 14. Schematic of the fabrication of the textile based DSSC developed by Pan. S. et al [69].

\subsection{Glass Based DSSC's}

Semi-closed tubular DSSC geometry has seen research in recent years, as the geometry of the cell allows for light to be trapped. The tubular cell is constructed from a dye sensitized porous $\mathrm{TiO}_{2}$ semi-closed glass tube which makes up the photoanode, and opaque platinum metal foil wrapped around the photoanode which acts as the counter electrode. This structure was prepared by Fang G. et al with a variety of structural parameters [70]. Interestingly, it was found 
that when the thickness of the porous $\mathrm{TiO}_{2}$ layer was $3.3 \mu \mathrm{m}$ and length was $3 \mathrm{~mm}$, the cell achieved the highest PCE in this study of $2.54 \%$. This suggests that modifying cell geometry may lead to the development of more efficient cells. However, the cell depended on light trapped within the cell, which makes its applications somewhat niche. Wang Z. et al explored a similar cell architecture based on optical fibers and obtained a PCE of 6\% [71]. The angle of the incidence angle of the light along with the power conversion efficiencies for the tubular cell design constructed by Fang G. et al are shown below in Figure 15. It is apparent that tuning of the structural parameters of the tubular cells can improve efficiency.
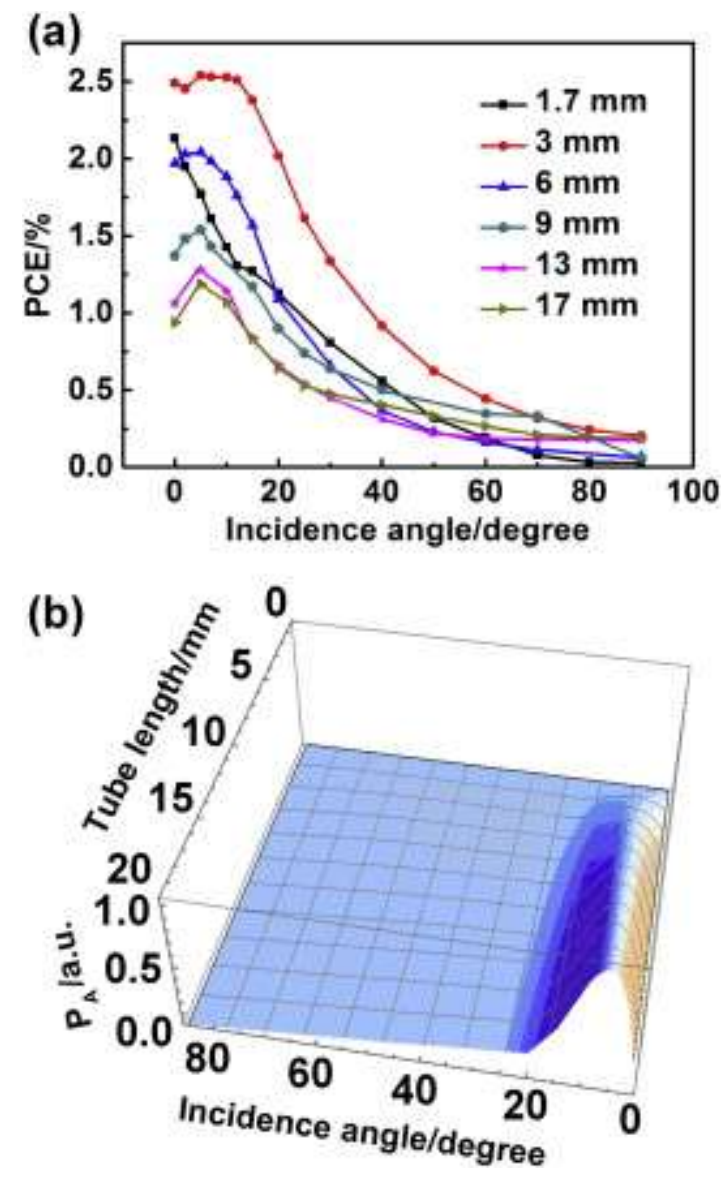

Figure 15. Experimental results of PCE/\% vs light incidence angle for different tubular cell lengths [70].

\section{CNT-Based 3-D Solid State Solar Cells}


A popular current area of research is the development of three-dimensional solar cells utilizing carbon nanotubes and solid state electrolytes. These cells promise to be cheap to manufacture (avoiding expensive metals), reasonably durable, and three-dimensionally structured to absorb light regardless of incident angle. The use of liquid electrolytes is still a major hurdle though; Zou et al in their 2015 review article of DSSC development noted that fiber type DSSCs made rapid progress in recent years, but also acknowledged that the use of a liquid or gel electrolyte impaired cell stability over time and limited the environments in which the cell could be deployed as the electrolyte could not be allowed to freeze or leak [72]. Okoli et al recently constructed a DSSC utilizing carbon nano-yarn as both the working and counter electrodes, with a $\mathrm{TiO}_{2}$ / dye microfilm coating on the working electrode as the functional part of the cell [73]. Okoli et al's use of all solid state cell components is advantageous as it gets around the problems posed by liquid electrolytes [73]. They obtained a maximum PCE of $2.57 \%$ and the cell showed stability over a prolonged period of time. Additionally, because of the threedimensional structure of the cell, it was able to convert incident photons regardless of direction [73]. A schematic of the cell produced by Okoli et al is shown in Figure 16.
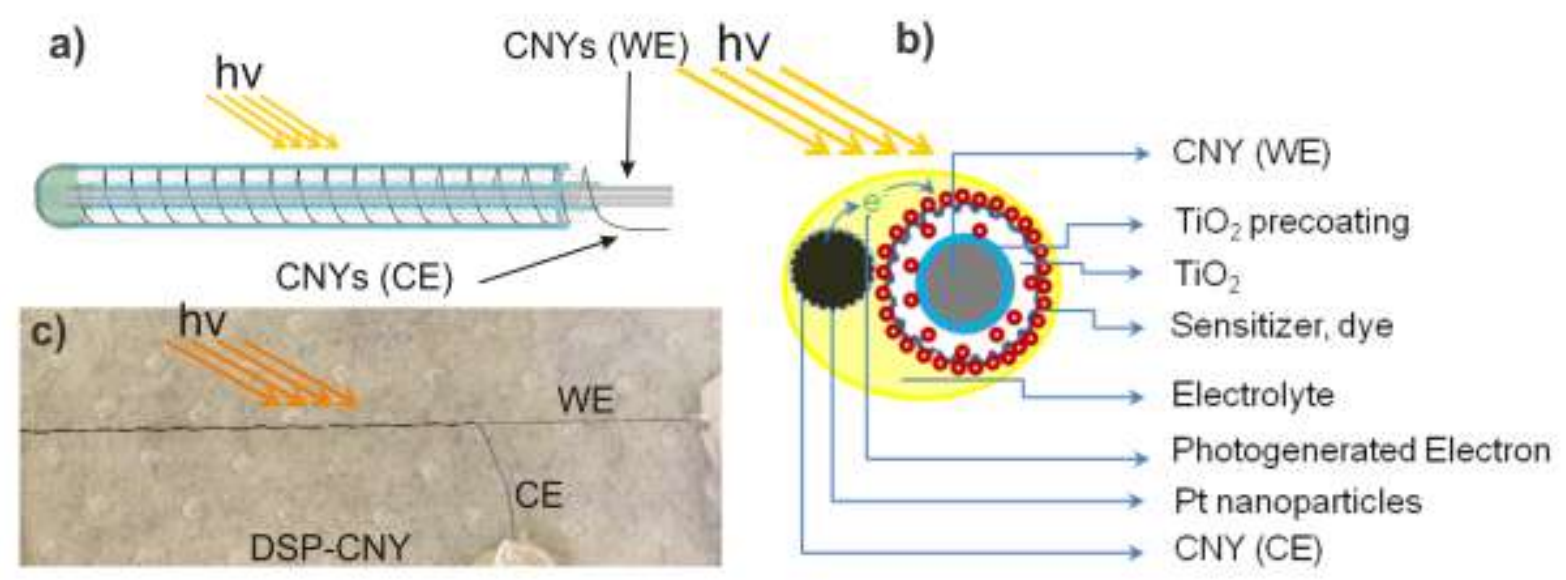

Figure 16. Schematic / picture of the CNY-based DSSC constructed by Okoli et al [73].

Okoli et al also explored the incorporation of a variety of sensitizers into the CNY-based 3-D DSSCs, including nanoporous $\mathrm{TiO}_{2}$, microporous $\mathrm{TiO}_{2}, \mathrm{CdS}, \mathrm{CdSe}$, and $\mathrm{N} 719$ dye, as well as the use of three twisted CNYs as an electrode rather than just a single CNY [74]. They found that the use of additional sensitizers improved cell performance, while the use of twisted CNYs rather than a single $\mathrm{CNY}$ decreased cell performance, likely due to the more complicated cell 
structure lowering conductivity [74]. Okoli et al managed to increase the PCE up to $6.4 \%$ with the use of additional sensitizers. A schematic representation of the incorporation of these additional sensitizers is shown in Figure 17 (a), and the uniformity of their distribution is apparent in Figure 17 (b).
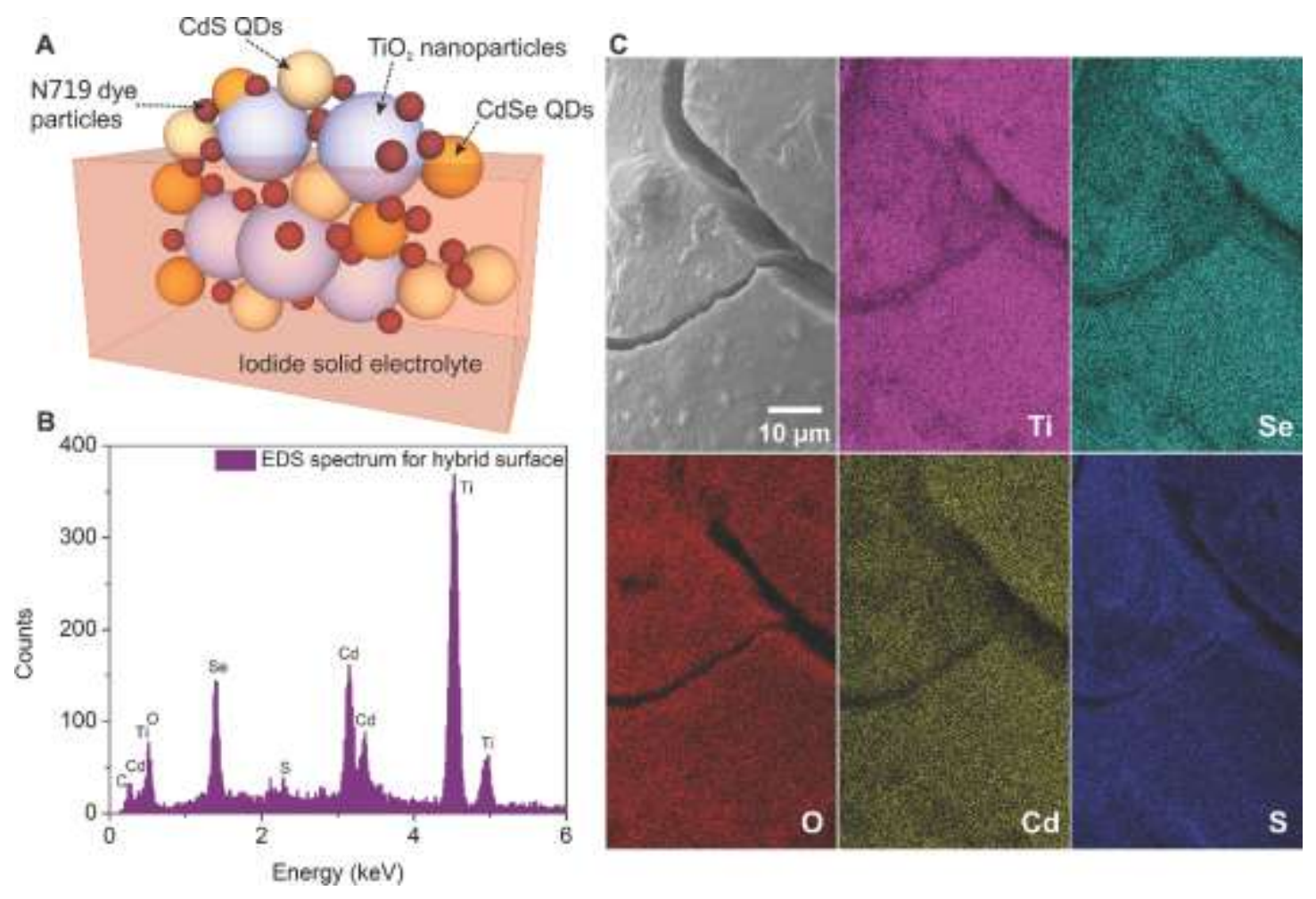

Figure 17. Distribution of the additional sensitizers to the 3D solar cells [74].

\section{Conclusion:}

Dye sensitized solar cells have seen rapid development in recent years. Integrating 3dimensional surface morphology, implementing different cell geometries, and incorporating a variety of sensitizers are all areas of active research. The shift from using platinum working electrodes and other exotic materials and fabrication processes towards simple and effective techniques will undoubtedly lower the price of these cells in the years to come. Fiber-type dye sensitized solar cells open up interesting textile applications and could potentially be used to construct wearable PV cells with integrated capacitors for energy storage. However, the low power energy conversion values that plague DSSCs (relative to conventional crystalline / 
polycrystalline cells) need to be overcome, or the cost of manufacturing DSSCs needs to fall substantially. If either of these happen it is likely that DSSC technology will see widespread commercial use. Further exploration of the unique properties of DSSCs (namely their flexibility, large PCE at high incident light angles, and ability to be manufactured into thread) could also lead to their widespread use in applications for which traditional solar cells are ill-suited. The observed PCE for flexible fiber-type DSSCs has increased substantially in recent years $(<0.5 \%$ to >9\%) [72], and while it may take time for DSSC PCE to catch up with that of traditional crystalline panels, rapid progress is currently being made. Good power conversion efficiencies have been observed; however, the highest PCE cells showed low long-term stability and large size. Likewise lightweight and stable devices have been demonstrated; however, they show relatively low power conversion efficiencies. With further research into optimizing cell characteristics synergistically, dye sensitized solar cell technology can likely be improved dramatically.

Acknowledgments

This research work was generously supported by a Welch Foundation Departmental Grant (BX0048). Jared Jaksik gratefully acknowledges the MSRDC and Department of Defense for his research fellowship thru Award \# D01_W911SR-14-2-0001-0003.

\section{References:}

1) R. Luna-Rubio, M. Trejo-Peria, D. Vargas-Vazquez, G.J. Rios-Moreno, Optimal sizing of renewable hybrids energy systems: a review of methodologies, Sol. Ener. 86 (2012) 1077-88.

2) G. Muller-Furstenberg, M. Wagner, Exploring the environmental Kuznets hypothesis: theoretical and environmental problem, Ecol. Econ. 62 (2007) 648-60.

3) R.H. Rainer, Renewable energy: paving the way towards sustainable energy security, Renew. Energy 49 (2013) 10-4.

4) W.A. Hermann, Quantifying global energy resources, Energy 31 (12) (2006) 1349-66.

5) Historical Data Workbook, BP Statistical Review of World Energy June 2014, http://www.bp.com/content/dam/bp-country/de_de/PDFs/brochures/BP-statistical-review-ofworld-energy-2014-full-report.pdf (accessed 9.7.2015)

6) International Energy Agency, Technology Roadmap: Solar Photovoltaic Energy, http://www.iea.org. (accessed 10.7.2015). 
7) M.A. Green, K. Emery, Y. Hishikawa, W. Warta, E. Dunlop, Solar cell efficiency tables (version 39), Prog. Photovoltaics Res. Appl. 20 (2012) 12-20.

8) M. Batmunkh, M.J. Biggs, J.G. Shapter, Carbon Nanotubes for Dye-Sensitized Solar Cells. Small 11 (2015) 2963-2989.

9) T. Sugaya, O. Numakami, R. Oshima, S. Furue, H. Komaki, T. Amano, K. Matsubara, Y. Okano, S. Niki, Ultra-high stacks of InGaAs quantum dots for high efficiency solar cells. Energy Environ. Sci. 20 (2012) 12-20.

10) J.D. Servaites, M.A. Ratner, T.J. Marks, Organic solar cells: a new look at traditional models, Energy Environ. Sci. 4 (2011) 4410-22.

11) S. Matthew, A. Yella, P. Gao, R. Humphry-Baker, B.F. Curchod, N. Ashari-Astani, I. Tavernelli, U. Rothlisberger, M.K. Nazeeruddin, M.Gratzel, Dye-sensitized solar cells with $13 \%$ efficiency achieved through the molecular engineering of porphyrin sensitizers, Nat. Chem. 6 (2014) 242.

12) A. Yella, H.W. Lee, H.N. Tsao, C. Yi, A.K. Chandiran, K. Nazeeruddin, E. Diau, C.Y. Yeh, S.M. Zakeeruddin, M. Gratzel, Porphyrin-sensitized solar cells with cobalt (II)(III)based redox electrolyte exceed 12 percent efficiency, Science 334(6056) (2011) 629-34.

13) H. Gerischer, M. Michel-Beyerle, E. Rebentrost, H. Tributsch, Sensitization of ChargeInjection into Semiconductors with Large Band Gap, Electrochim. Acta 13 (1968) 15091515.

14) Heliatek, Heliatek sets new Organic Photovoltaic world record efficiency of $13.2 \%$. http://www.heliatek.com/en/press/press-releases/details/heliatek-sets-new-organicphotovoltaic-world-record-efficiency-of-13-2 (accessed 20.2.2017).

15) J.M. Uddin, D.E. Daramola, E. Velasquez, T.J. Dickens, J. Yan, E. Hammel, F. Cesano, O.I. Okoli, A high efficiency 3D photovoltaic microwire with carbon nanotubes (CNT)quantum dot (QD) hybrid interface, Phys. Status Solidi RRL (2014) 1-6.

16) J. Jinbiao, J. Wu, Y. Tu, J. Huo, M. Zheng, J. Lin, Transparent nickel selenide used as counter electrode in high efficient dye-sensitized solar cells, J. Alloys Compd. 640 (2015) 29-33.

17) A. Kay, M. Gratzel, Low cost photovoltaic modules based on dye sensitized nanocrystalline titanium dioxide and carbon powder, Sol. Energ. Mat. Sol. Cells 44 (1996) 99-117. 
18) G. Guan, Z. Yang, L. Qiu, X. Sun, Z. Zhang, J. Ren, H. Peng, Oriented PEDOT:PSS on aligned carbón nanotubes for efficient dye-sensitized solar cells, J. Mater. Chem. 1 (2013) 13268-13273.

19) L. Qiu, Q. Wu, Z. Yang, X. Sun, Y. Zhang, H. Peng, Freestanding Aligned Carbon Nanotube Array Grown on a Large-Area Single-Layered Graphene Sheet for Efficient DyeSensitized Solar Cell, Small 11 (2015) 1150-1155.

20) S. Huang, L. Li, Z. Yang, L. Zhang, H. Saiyin, T. Chen, H. Peng, A New and General Fabrication of an Aligned Carbon Nanotube/Polymer Film for Electrode Applications, Adv. Mater. 23(40) (2011) 4707-4710.

21) J. Yan, M.J. Uddin, O.I. Okoli, Carbon Nano Tubes (CNTs) enrich the solar cells, Sol. Ener. 96 (2013) 239-252.

22) X. Fan, Z.Z. Chu, F.Z. Wang, C. Zhang, L. Chen, Y.W. Tang, D.C. Zou, Wire-shaped flexible dye-sensitized solar cells, Adv. Mater. 20(3) (2008) 592.

23) S.W. Chou, H.C. Chen, Z. Zhang, W.H. Tseng, C.I. Wu, Y.Y. Yang, C.Y. Lin, P.T. Chou, Strategic Design of Three-Dimensional (3D) Urchin-Like Pt-Ni Nanoalloys: How this unique nanostructure boosts the bulk heterojunction polymer solar cells efficiency to $8.48 \%$, Chem. Mater. 26 (2014) 7029-38.

24) S. Zhang, C. Ji, Z. Bian, R. Liu, X. Xia, D. Yun, L. Zhang, C. Huang, A. Cao, Single-Wire Dye-Sensitized Solar Cells Wrapped by Carbon Nanotube Film Electrodes, Nano Lett. 11 (2011) 3383-3387.

25) M. Torresan, A.M. Baruzzi, R.A. Iglesias, Thermal annealing of photoanodes based on CdSe Qdots sensitized $\mathrm{TiO}_{2}$, Sol. Energ. Mat. Sol. Cells 155 (2016) 202-208.

26) A. Kongkanand, K. Tvrdy, K. Takechi, M. Kuno, P.V. Kamat, Quantum Dot Solar Cells. Tuning Photoresponse through Size and Shape Control of $\mathrm{CdSe}-\mathrm{TiO}_{2}$ Architecture, J. Am. Chem. Soc. 130 (2008) 4007-4015.

27) C.B. Murray, D.J. Norris, M.G. Bawendi, Synthesis and characterization of nearly monodisperse $\mathrm{CdE}$ ( $\mathrm{E}=$ sulfur, selenium, tellurium) semiconductor nanocrystallites, J. Am. Chem. Soc. 115 (1993) 8706-8715.

28) B.O. Dabbousi, J. Rodriguez-Viejo, F.V. Mikulec, J.R. Heine, H. Mattoussi, R. Ober, K.F. Jensen, M.G. Bawendi, $(\mathrm{CdSe}) \mathrm{ZnS}$ Core-Shell Quantum Dots: Synthesis and 
Characterization of a Size Series of Highly Luminescent Nanocrystallites, J. Phys. Chem. B 101 (1997) 9463-9475.

29) W.C. Chan, D.J. Maxwell, X. Gao, R.E. Bailey, M. Han, S. Nie, Luminescent quantum dots for multiplexed biological detection and imaging, Curr. Opinion in Biotech. 13 (2002) 4046.

30) C. Chen, Y. Cheng, J. jin, Q. Dai, H. Song, CdS/CdSe quantum dots and $\mathrm{ZnPc}$ dye cosensitized solar cells with Au nanoparticles/graphene oxide as efficient modified layer, J. Colloid Interface Sci. 480 (2016) 49-56.

31) F.D. Angelis, S. Fantacci, E. Mosconi, M.K. Nazeeruddin, M. Grätzel, Absorption Spectra and Excited State Energy Levels of the N719 Dye on $\mathrm{TiO}_{2}$ in Dye-Sensitized Solar Cell Models, J. Phys. Chem. C 115 (2011) 8825-831.

32) J.N. Coleman, U. Khan, W.J. Blau, Y.K. Gun'ko, Small but Strong: A Review of the Mechanical Properties of Carbon Nanotube-polymer Composites, Carbon 44 (2006) 16241652.

33) E. Pop, D. Mann, Q. Wang, K. Goodson, H. Dai, Thermal conductance of an individual single-wall carbon nanotube above room temperature, Nano Lett. 6 (2006) 96-100.

34) V. Derycke, R. Martel, J. Appenzeller, P. Avouris, Carbon Nanotube Inter- and Intramolecular Logic Gates, Nano Lett. 1 (2001) 453-456.

35) R.H. Baughman, A.A. Zakhidov, W.A. de Heer, Carbon Nanotubes: the Route Toward Applications, Science 297 (2002) 787-792.

36) National Nanotechnology Initiative, Technical Interchange Proceedings Realizing the Promise of Carbon Nanotubes: Challenges, Opportunities, and the Pathway to Commercialization,

http://www.nano.gov/sites/default/files/pub_resource/2014_nni_cnt_tech_meeting_report.pdf (accessed 10.6.2015).

37) A. Aqel, K.M. Abou El-Nour, R.A. Ammar, A. Al-Warthan, Carbon Nanotubes, Science and Technology Part (I) Structure, Synthesis and Characterisation, Arabian J. Chem. 5 (2012) 1-23.

38) J. Han, H. Kim, D.Y. Kim, S.M. Jo, S.Y. Jang, Water-Soluble Polyelectrolyte-Grafted Multiwalled Carbon Nanotube Film for Efficient Counter Electrode of Dye-Sensitized Solar Cells, ACS Nano 4 (2010) 3503-3509. 
39) P.V. Kamat, K.G. Thomas, S. Barazzouk, G. Girishkumar, K. Vinodgopal, D. Meisel, SelfAssembled Linear Bundles of Single Wall Carbon Nanotubes and Their Alignment and Deposition as a Film in a Dc Field, J. Am. Chem. Soc. 126 (2004) 10757-10762.

40) L. Wei, N. Teznuka, T. Umeyama, H. Imahori, Y. Chen, Formation of single-walled carbon nanotube thin films enriched with semiconducting nanotubes and their application in photoelectrochemical devices, Nanoscale 3 (2011) 845-1849.

41) A. Jelen., V. Bukosek, J. Dolinsek, Viscoelastic Properties and Reinforcement Performance of the $\mathrm{MoS}_{2}$ Nanotubes-polymer Composite, Int. J. Mater. Sci. 2.1 (2012) 20-26.

42) X. Liu, T. Pichler, M. Knupfer, M.S. Golden, J. Fink, H. Kataura, Y. Achiba, Detailed Analysis of the Mean Diameter and Diameter Distribution of Single-wall Carbon Nanotubes from Their Optical Response, Phys. Rev. B 66 (2002) 045411.

43) Y.M. Choi, H. Choo, H. Yeo, N.H. You, D.S. Lee, B.C. Ku, H.C. Kim, P.H. Bong, Y. Jeong, M. Goh, Chemical Method for Improving Both the Electrical Conductivity and Mechanical Properties of Carbon Nanotube Yarn via Intramolecular Cross-Dehydrogenative Coupling, ACS Appl. Mater. Interfaces 5(16) (2013) 7726-7730.

44) T. Ni, J, Yan, Y. Jiang, F. Zou, L. Zhang, D. Yang, J. qei, S. Yang, B. Zou, Enhancement of the power conversion efficiency of polymer solar cells by functionalized single-walled carbon nanotubes decorated with $\mathrm{CdSe} / \mathrm{ZnS}$ core-shell colloidal quantum dots, J. Mater. Sci. 49 (2014) 2571-2577.

45) B.K. Sahu, A study on global solar PV energy developments and policies with special focus on the top ten solar PV power producing countries, Renewable Sustainable Energy Rev. 43 (2015) 621-634.

46) W.A. Hermann, Quantifying global exergy resources. Energy 31(12) (2006) 1349-66.

47) M.A. Green, K. Emery, Y. Hishikawa, W. Warta, E.D. Dunlop, Solar cell efficiency tables (version 39), Prog. Photovoltaics Res. Appl. 20 (2012) 12-20.

48) L. Song, Y. Guan, P. Du, Y. Yang, F. Ko, J. Xiong, Enhanced efficiency in flexible dyesensitized solar cells by a novel bilayer photoanode made of carbon nanotubes incorporated $\mathrm{TiO}_{2}$ nanorods and branched $\mathrm{TiO}_{2}$ nanotubes, Sol. Energy Mater. Sol. Cells 147 (2016) 134143. 
49) A.A. Arbab, K.C. Sun, I.A. Sahito, S.H. Jeong, Multiwalled carbon nanotube coated polyester fabric as textile based flexible counter electrode for dye sensitized solar cell, Phys. Chem. Chem. Phys. 17 (2015) 12957-12969.

50) Q. Hou, Y. Zheng, J.F. Chen, W. Zhou, J. Deng, X. Tao, Visible-light-response iodinedoped titanium dioxide nanocrystals for dye-sensitized solar cells, J. Mater. Chem. 21 (2011) 3877.

51) Z. Yang, H. Sun, T. Chen, L. Qiu, Y. Luo, H. Peng, Photovoltaic Wire Derived from a Graphene Composite Fiber Achieving an 8.45\% Energy Conversion Efficiency, Angew. Chem. 52(29) (2013) 7545-7548.

52) T. Chen, L. Qiu, Z. Cai, F. Gong, Z. Yang, Z. Wang, H. Peng, Intertwined Aligned Carbon Nanotube Fiber Based Dye-Sensitized Solar Cells, Nano Lett. 12(5) (2012) 2568-2572.

53) X. Ma, H. Elbohy, S. Sigdel, C. Lai, Q. Qiao, H. Fong, Electrospun carbon nano-felt derived from alkali lignin for cost-effective counter electrodes of dye-sensitized solar cells, RSC Adv. 6(14) (2016) 11481-11487.

54) D.A. Grynko, A.N. Fedoryak, P.S. Smertenko, O.P. Dimitriev, N.A. Ogurstov, A.A. Pud, Hybrid solar cell on a carbon fiber, Nanoscale Res. Lett. 11 (2016) 265.

55) L. Chen, Y. Zhou, H. Dai, T. Yu, J. Liu, Z. Zou, One-step growth of $\mathrm{CoNi}_{2} \mathrm{~S}_{4}$ nanoribbons on carbon fibers as platinum-free counter electrodes for fiber-shaped dye-sensitized solar cells with high performance: Polymorph-dependent conversion efficiency, Nano Energy 11 $(2$

56) 014) 697-703.

57) J. Liang, G. Zhang, J. Yin, Y. Yang, Transparent, 3-dimensional light-collected, and flexible fiber-type dye-sensitized solar cells based on highly ordered hierarchical anatase $\mathrm{TiO}_{2}$ nanorod arrays, J. Power Sources 272 (2014) 719-729.

58) M. Peng, X. Cai, Y. Fu, X. Yu, S. Liu, B. Deng, K. Hany, D. Zou, Facial synthesis of $\mathrm{SnO}_{2}$ nanoparticle film for efficient fiber-shaped dye-sensitized solar cells, J. Power Sources 247 (2014) 249-255.

59) M. Peng, X. Yu, X. Cai, Q. Yang, H. Hu, K. Yan, H. Wang, B. Dong, F. Zhu, D. Zou, Waveguide fiber dye-sensitized solar cells, Nano Energy 10 (2014) 117-124. 
60) G. Liu, X. Gao, H. Wang, A.Y. Kim, Z. Zhao, J.K. Lee, D. Zou, A novel photoanode with high-flexibility for fiber-shaped dye sensitized solar cells, J. Mater. Chem. 4(6) (2016) 5295-5931.

61) M.J. Uddin, F. Cesano, F. Bonino, S. Bordiga, G. Spoto, D. Scarano, A. Zecchina, Photoactive $\mathrm{TiO}_{2}$ films on cellulose fibres: synthesis and characterization, J. Photochem. Photobiol., A 189 (2007) 286-294.

62) Z. Li, Y. Zhou, Y. Yang, H. Dai, Electrophoretic deposition of graphene-TiO 2 hierarchical spheres onto Ti thread for flexible fiber-shaped dye-sensitized solar cells, Mater. Des. 105 (2016) 352-358.

63) Y. Rui, Y. Wang, Q. Zhang, Q. Chi, M. Zhang, H. Wang, Y. Li, C. Hou, In-situ construction of three-dimensional titania network on Ti foil toward enhanced performance of flexible dye-sensitized solar cells, Appl. Surf. Sci. 380 (2016) 210-217.

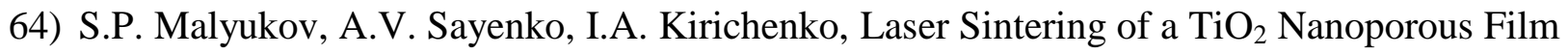
on a Flexible Substrate for Application in Solar Cells, Semiconductors 50(9) (2016) 11981202.

65) W. Hou, Y. Xiao, G. Han, D. Fu, R. Wu, Serrated, flexible and ultrathin polyaniline nanoribbons: An efficient counter electrode for the dye-sensitized solar cell, J. Power Sources 332 (2016) 155-162.

66) M. Gerosa, A. Sacco, A. Scalia, F. Bella, A. Chiodoni, M. Quaglio, E. Tresso, S. Bianco, Toward Totally Flexible Dye-Sensitized Solar Cells Based on Titanium Grids and Polymeric Electrolytes, IEEE J. Photovoltaics 6 (2016) 498-504.

67) Q. Xu, M. Li, P. Yan, C. Wei, L. Fang, W. Wei, H. Bao, J. Xu, W. Xu, Polypyrrole-coated cotton fabrics prepared by electrochemical polymerization as textile counter electrodes for dye-sensitized solar cells, Org. Electron. 29 (2016) 107-113.

68) K. Opwis, J.S. Gutmann, A.R Lagunas Alonso, M.J. Rodriguez Henche, M.E. Mayo, F. Breil, E. Leonardi, L. Sorbello, Preparation of a Textile-Based Dye-Sensitized Solar Cell, Int. J. Photoenergy (2016) 3796074.

69) I.A. Sahito, K.C. Sun, A.A. Arbab, M.B. Qadir, Y.S. Choi, S.H. Jeong, Flexible and conductive cotton fabric counter electrode coated with graphene nanosheets for high efficiency dye sensitized solar cell, J. Power Sources 319 (2016) 90-98. 
70) S. Pan, Z. Yang, P. Chen, J. Deng, H. Li, H. Peng, Wearable Solar Cells by Stacking Textile Electrodes, Angew. Chem. Int. Ed. 53 (2014) 6110-6114.

71) W. Zeng, M. Wang, Y. Li, J. Wan, H. Huang, H. Tao, D.L. Carroll, X. Zhao, D. Zou, G. Fang, Semi-closed tubular light-trapping geometry dye sensitized solar cells with stable efficiency in wide light intensity range, J. Power Sources 261 (2014) 75-85.

72) W. Guo, C. Xu, G. Zhu, C. Pan, C. Lin, Z.L. Wang, Optical-fiber/TiO 2 -nanowire-arrays hybrid structures with tubular counterelectrode for dye-sensitized solar cell, Nano Energy 1 (2012) 176-182.

73) M. Peng, D. Zou, Flexible fiber/wire-shaped solar cells in progress: properties, materials, and designs, J. Mater. Chem. A 41 (2015) 20435.

74) J. Yan, M.J. Uddin, T.J. Dickens, D.E. Daramola, O.I. Okoli, 3D Wire-Shaped DyeSensitized Solar Cells in Solid State Using Carbon Nanotube Yarns with Hybrid Photovoltaic Structure, Adv. Mater. Interfaces 1(6) (2014) 1400075.

75) M.J. Uddin, D.E. Daramola, E. Velasquez, T.J. Dickens, J. Yan, E. Hammel, F. Cesano, O.I. Okoli, A high efficiency 3D photovoltaic microwire with carbon nanotubes (CNT)quantum dot (QD) hybrid interface, Phys. Status Solidi RRL 11 (2014) 898-903. 